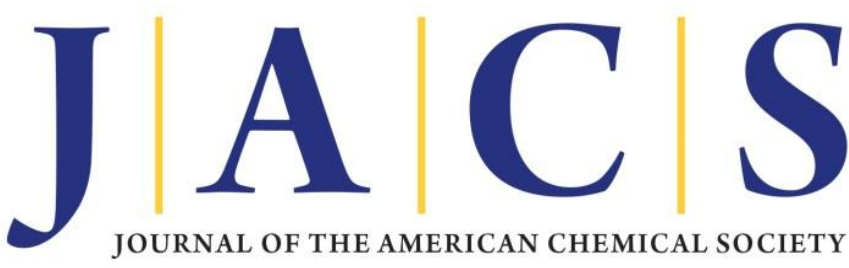

\title{
Discrete Open-Shell Tris(Bipyridinium Radical Cationic) Inclusion Complexes in the Solid State
}

Ommid Anamimoghadam, ${ }^{\dagger}$ Leighton O. Jones, ${ }^{\dagger}$ James A. Cooper, ${ }^{\dagger, \pm}$ Yassine Beldjoudi, ${ }^{\dagger}$ Minh T. Nguyen, ${ }^{\dagger}$ Wenqi Liu, ${ }^{\dagger}$ Matthew D. Krzyaniak, ${ }^{\dagger, \dagger}$ Cristian Pezzato, ${ }^{\dagger},{ }^{\ddagger}$ Charlotte L. Stern, ${ }^{\dagger}$

Hasmukh A. Patel,$^{\dagger}$ Michael R. Wasielewski, ${ }^{\dagger, \dagger}$ George C. Schatz, ${ }^{\dagger}$ J. Fraser Stoddart ${ }^{\dagger,},, \#,{ }^{*} \dagger$

Department of Chemistry, Northwestern University, 2145 Sheridan Road, Evanston, IL 60208, United States

${ }^{\sharp}$ Institute for Sustainability and Energy at Northwestern, Northwestern University,

2145 Sheridan Road, Evanston, IL 60208, United States

§Institute for Molecular Design and Synthesis, Tianjin University, 92 Weijin Road,

Nankai District, Tianjin, 300072, P. R. China

\#School of Chemistry, University of New South Wales, Sydney, NSW 2052, Australia

*E-mail: stoddart@northwestern.edu

\section{SUPPORTING INFORMATION}

\section{Table of Contents}

1. Materials / General Methods / Instrumentation...............................

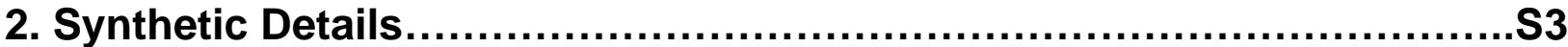

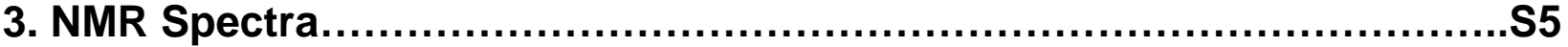

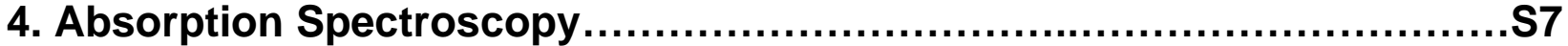

5. Electrochemistry: Cyclic Voltammetry.......................................... 9

6. X-Ray Crystal (Super)structures...................................................

7. Titration Experiments.................................................................

8. Density Functional Theory Calculations....................................... 22

9. Electron Paramagnetic Resonance Spectroscopy...........................S22

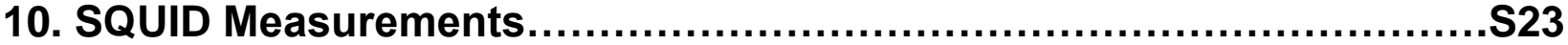

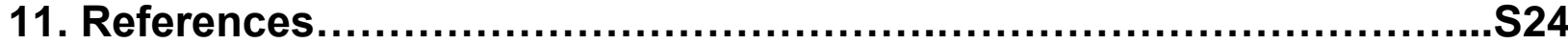




\section{Materials / General Methods / Instrumentation}

All reagents were purchased from commercial suppliers and used without further purification unless stated otherwise. Commercial grades of anhydrous MeCN solvent were used in all reactions. Zn dust was activated by stirring with $1 \mathrm{M} \mathrm{HCl}$ solution for $20 \mathrm{~min}$, filtered by vacuum suction, washed with $\mathrm{H}_{2} \mathrm{O}, \mathrm{EtOH}$, and $\mathrm{Et}_{2} \mathrm{O}$ and dried under vacuum prior to its use as reducing agent. 2,5Bis(bromomethyl)-1,4-dimethoxybenzene was prepared according to a literature procedure. ${ }^{1}$ Thin layer chromatography (TLC) was performed on silica gel 60F254 (E Merck). Column chromatography was carried out on silica gel 60F (Merck 9385, 0.040-0.063 mm). High performance liquid chromatography was performed using a reverse-phase $\mathrm{XBridge}^{\mathrm{TM}}$ Preparative $\mathrm{C}_{18} / 5 \mu \mathrm{m}$ column, connected to a LC-8A SHIMADZU instrument and controlled by SHIMADZU EZStart (Vers. 7.4 SP1 Build 15) software. The detector was set to $\lambda=254 \mathrm{~nm}$. The eluents used were $\mathrm{MeCN}$ and $\mathrm{H}_{2} \mathrm{O}$, mixed with $0.1 \%$ (v/v) trifluoroacetic acid (TFA). UV-Vis-NIR spectra were recorded by a SHIMADZU UV-3600 UV-Vis-NIR spectrophotometer with the aid of SHIMADZU UV Probe 2.33 software. For operation under oxygen-free conditions, UV-Vis-NIR measurements were carried out using a $10 \mathrm{~mm}$ quartz cuvette (9F-Q-10-GL14-C from Starna Cells, Inc) with a closed screw cap. Nuclear magnetic resonance (NMR) spectra were recorded on a Bruker F500 spectrometer, with working frequencies of $500 \mathrm{MHz}\left({ }^{1} \mathrm{H} \mathrm{NMR}\right)$, and $125 \mathrm{MHz}\left({ }^{13} \mathrm{C}\right.$ NMR), respectively. Chemical shifts are reported in ppm relative to the signals corresponding to the residual non-deuterated solvents $\left(\mathrm{CDCl}_{3}: \delta_{\mathrm{H}}=7.24 \mathrm{ppm}\right.$ and $\delta_{\mathrm{C}}=77.36 \mathrm{ppm}, \mathrm{CD}_{3} \mathrm{CN}: \delta_{\mathrm{H}}=1.94$ ppm and $\delta_{\mathrm{C}}=1.79$ and $\left.118.26 \mathrm{ppm}\right)$. High-resolution mass spectra (HRMS) were measured on an Agilent 6210 Time of Flight (TOF) LC-MS, using an ESI source, coupled with Agilent 1100 HPLC stack, using direct infusion $(0.6 \mathrm{~mL} / \mathrm{min})$. Cyclic voltammetry $(\mathrm{CV})$ was conducted with a Gamry Instruments Reference600 potentiostat using a three-electrode setup, utilizing a glassy carbon working electrode of area $0.071 \mathrm{~cm}^{2}$, a Pt counter electrode and an $\mathrm{Ag} / \mathrm{AgNO}_{3}$ reference electrode. $\mathrm{X}$-Ray crystal (super)structural analyses were carried out by transferring crystals immersed in inert oil to the cold gas stream of a Kappa Apex 2 diffractometer. Crystals were kept at $100 \mathrm{~K}$ during data collections. Using Olex $2{ }^{2}$ the (super)structures were solved with the ShelXT ${ }^{3}$ structure solution program using Direct Methods and refined with the ShelXL ${ }^{4}$ refinement package using Least Squares minimization. 


\section{Synthetic Details}

\section{Full Synthesis}

Cyclobis(paraquat- $p$-1,4-dimethoxyphenylene) tetrakis(hexafluorophosphate) $\left(\mathbf{1} \cdot 4 \mathrm{PF}_{6}\right)$ was synthesized in two steps. The synthetic procedures and data for each step are described in this Section. 2,5-Bis(bromomethyl)-1,4-dimethoxybenzene was prepared as reported previously. ${ }^{1}$<smiles>c1cc(-c2ccncc2)ccn1</smiles>

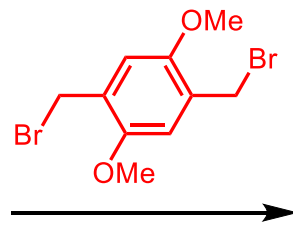

1.MeCN / Reflux 2. $\mathrm{NH}_{4} \mathrm{PF}_{6} / \mathrm{H}_{2} \mathrm{O}$

$80 \%$

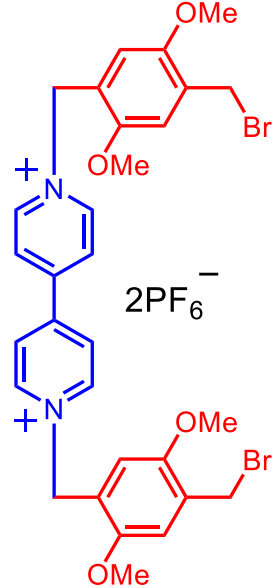

$2 \cdot 2 \mathrm{PF}_{6}$<smiles>c1cc(-c2ccncc2)ccn1</smiles>

1.TBAI / MeCN $110^{\circ} \mathrm{C} / 6 \mathrm{psi}$ 2. $\mathrm{NH}_{4} \mathrm{PF}_{6} / \mathrm{H}_{2} \mathrm{O}$

$12 \%$

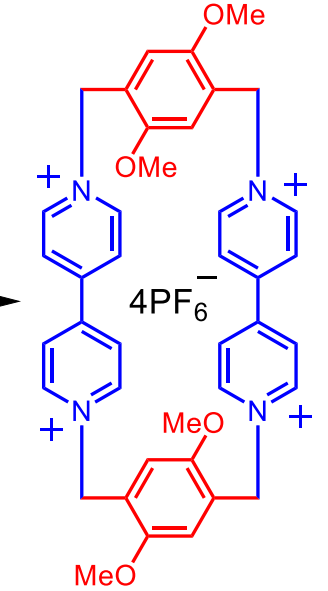

$1 \cdot 4 \mathrm{PF}_{6}$

Scheme S1. Full Synthesis of 1.4PF 6

\section{1,1'-Bis(2-(bromomethyl)-1,4-dimethoxybenzyl)-4,4'-bipyridinium hexafluorophosphate $\left(2 \cdot 2 \mathrm{PF}_{6}\right)$}
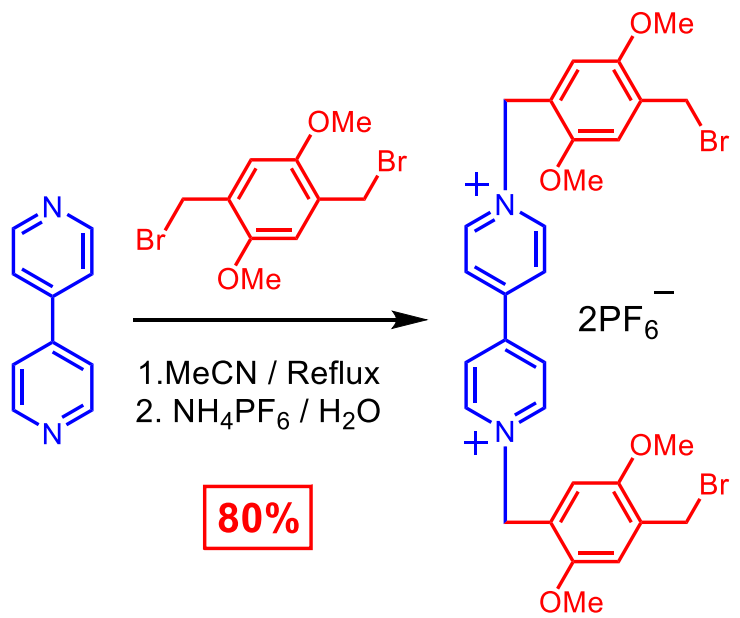

$2 \cdot 2 \mathrm{PF}_{6}$

Scheme S2. Synthesis of $2 \cdot 2 P F_{6}$ 
2•2PF6: 4,4'-Bipyridine (324 mg, $2.07 \mathrm{mmol}$ ) was dissolved in dry MeCN (20 mL) and added dropwise to a stirred solution of 2,5-bis(bromomethyl)-1,4-dimethoxybenzene (4.7 g, $14.51 \mathrm{mmol})$ in dry $\mathrm{MeCN}(300 \mathrm{~mL})$ at $90{ }^{\circ} \mathrm{C}$ with the aid of a syringe pump over the course of $6 \mathrm{~h}$. The solution was then stirred at the same temperature for $18 \mathrm{~h}$. Thereafter, an excess of TBACl was added to the yellow solution, resulting in a yellow precipitate which was filtered by vacuum filtration using a sinter funnel. The residue was subsequently washed with $\mathrm{CH}_{2} \mathrm{Cl}_{2}$ and the yellow residue was dissolved in distilled $\mathrm{H}_{2} \mathrm{O}$ and immediately mixed with a saturated solution of $\mathrm{NH}_{4} \mathrm{PF}_{6}$ leading to immediate precipitation of the desired $\mathrm{PF}_{6}{ }^{-}$salt. Prompt ion-exchange was necessary since the dibromide appeared to decompose readily by nucleophilic attack, in which the bromides are replaced by hydroxyl groups. The pale-yellow powder was then separated by centrifugation and washed with distilled $\mathrm{H}_{2} \mathrm{O}$ three times to remove the excess of $\mathrm{NH}_{4} \mathrm{PF}_{6}$. After drying, $\mathbf{2} \cdot 2 \mathrm{PF}_{6}$ was obtained as yellow powder $(1.54 \mathrm{~g}, 80 \%) .{ }^{1} \mathrm{H}-\mathrm{NMR}\left(500 \mathrm{MHz}, \mathrm{CD}_{3} \mathrm{CN}\right): \delta 8.99(\mathrm{~d}, J=6.1 \mathrm{~Hz}$, 4H), $8.30(\mathrm{~d}, J=6.0 \mathrm{~Hz}, 4 \mathrm{H}), 7.28(\mathrm{~s}, 2 \mathrm{H}), 7.11(\mathrm{~s}, 2 \mathrm{H}), 5.71(\mathrm{~s}, 4 \mathrm{H}), 4.58(\mathrm{~s}, 4 \mathrm{H}), 3.92(\mathrm{~s}, 6 \mathrm{H})$, $3.78(\mathrm{~s}, 6 \mathrm{H}) .{ }^{13} \mathrm{C}-\mathrm{NMR}\left(125 \mathrm{MHz}, \mathrm{CD}_{3} \mathrm{CN}\right): \delta 29.6,57.4,57.6,62.5,115.7,116.6,123.2,128.4$, 131.1, 147.3, 151.6, 153.0, 153.3. HRMS (ESI) calcd for $\mathrm{C}_{30} \mathrm{H}_{32} \mathrm{Br}_{2} \mathrm{~F}_{12} \mathrm{~N}_{2} \mathrm{O}_{4} \mathrm{P}_{2}: m / z=789.0347[M$ $\left.-\mathrm{PF}_{6}\right]^{+}$, found: $m / z=789.0354\left[M-\mathrm{PF}_{6}\right]^{+}$.

\section{Cyclobis(paraquat- $p$-1,4-dimethoxyphenylene) hexafluorophosphate (1•4PF6)}

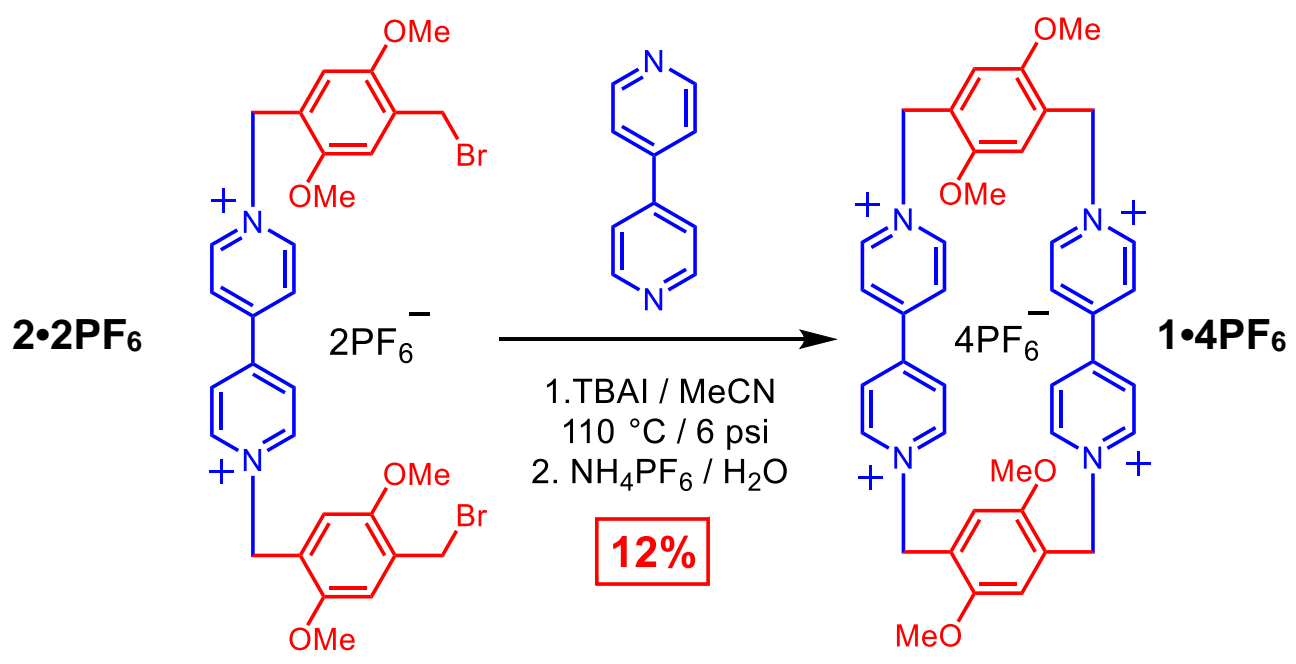

Scheme S3. Synthesis of 1.4PF6 
1•2PF6: 4,4'-Bipyridine (67 mg, $0.43 \mathrm{mmol}$ ), $\mathbf{2} \cdot \mathrm{PF}_{6}$ (400 $\mathrm{mg}$; $0.43 \mathrm{mmol}$ ) and TBAI (32 $\mathrm{mg}, 87$ $\mu \mathrm{mol})$ were heated in dry $\mathrm{MeCN}(500 \mathrm{~mL})$, up to $110^{\circ} \mathrm{C}$ at a pressure of 6 psi above atmosphere for $12 \mathrm{~h}$. Afterwards, the solvent volume was reduced by rotary evaporation and an excess of TBACl was added to the mixture, resulting in precipitation of the corresponding $\mathrm{Cl}^{-}$salts. The precipitate was separated by centrifugation and washed with $\mathrm{MeCN}$ three times and subsequently dried under air. The crude solid was then dissolved in distilled $\mathrm{H}_{2} \mathrm{O}$ and filtered through a nylon syringe filter with $0.2 \mu \mathrm{m}$ pore size. The aqueous filtrate was subjected to HPLC and the first fraction containing the desired product was obtained in few minutes. The aqueous solution was treated with $\mathrm{NH}_{4} \mathrm{PF}_{6}$, resulting in precipitation of the cyclophane as the $\mathrm{PF}_{6}{ }^{-}$salt and subsequently separated by centrifugation, washed with distilled $\mathrm{H}_{2} \mathrm{O}$ three times and dried under air which gave $1 \cdot 2 \mathrm{PF}_{6}$ as a yellow solid $(63 \mathrm{mg}, 12 \%) .{ }^{1} \mathrm{H}-\mathrm{NMR}\left(500 \mathrm{MHz}, \mathrm{CD}_{3} \mathrm{CN}\right): \delta 8.89(\mathrm{~d}, J=6.9 \mathrm{~Hz}, 8 \mathrm{H})$, $8.16(\mathrm{~d}, J=6.9 \mathrm{~Hz}, 8 \mathrm{H}), 7.15(\mathrm{~s}, 4 \mathrm{H}), 5.70(\mathrm{~s}, 8 \mathrm{H}), 3.86(\mathrm{~s}, 12 \mathrm{H}) .{ }^{13} \mathrm{C}-\mathrm{NMR}\left(125 \mathrm{MHz}, \mathrm{CD}_{3} \mathrm{CN}\right)$ : $\delta$ 57.1, 60.8, 115.4, 126.0, 127.7, 146.5, 150.2, 152.2. UV (in MeCN) $\lambda_{\max }[\mathrm{nm}](\varepsilon): 261$ (53801 $\left.\mathrm{M}^{-1} \mathrm{~cm}^{-1}\right), 390\left(3858 \mathrm{M}^{-1} \mathrm{~cm}^{-1}\right)$. HRMS (ESI) calcd for $\mathrm{C}_{40} \mathrm{H}_{40} \mathrm{~F}_{24} \mathrm{~N}_{4} \mathrm{O}_{4} \mathrm{P}_{4}: m / z=1075.1969[M-$ $\left.\mathrm{PF}_{6}\right]^{+}$, Found: $m / z=1075.1975\left[M-\mathrm{PF}_{6}\right]^{+} ; m / z=465.1161\left[M-2 \mathrm{PF}_{6}\right]^{2+}$, Found: $m / z=465.1179$ $\left[M-2 \mathrm{PF}_{6}\right]^{+} ; m / z=929.2249\left[M-\left(\mathrm{HPF}_{6}+\mathrm{PF}_{6}\right)\right]^{2+}$, Found: $m / z=929.2253\left[M-\left(\mathrm{HPF}_{6}+\mathrm{PF}_{6}\right)\right]^{2+}$.

\section{NMR Spectra}

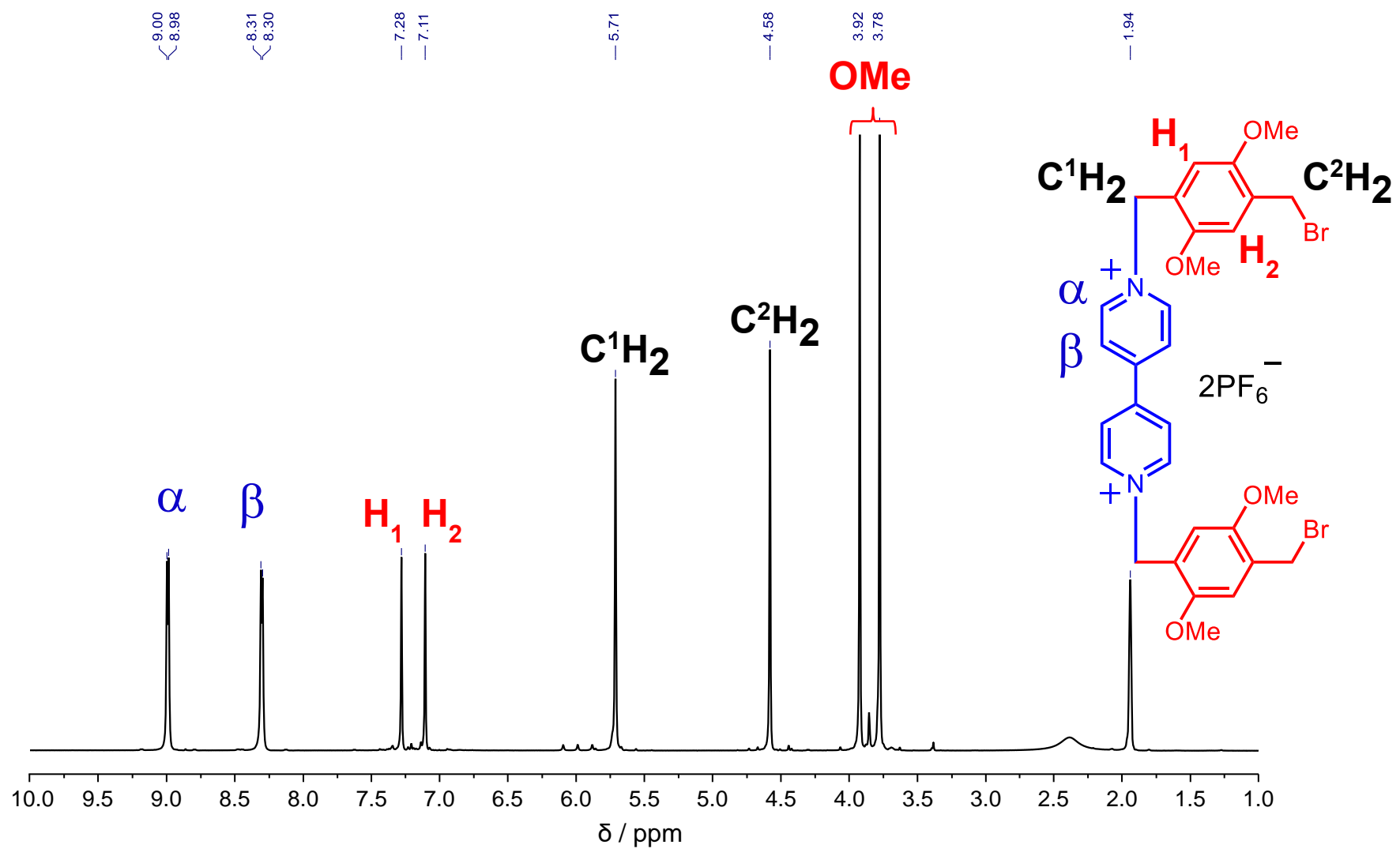

Figure S1. ${ }^{1} \mathrm{H}$ NMR Spectrum of $2 \cdot 2 \mathrm{PF}_{6}$ recorded in $\mathrm{CD}_{3} \mathrm{CN}$ at $293 \mathrm{~K}$ 


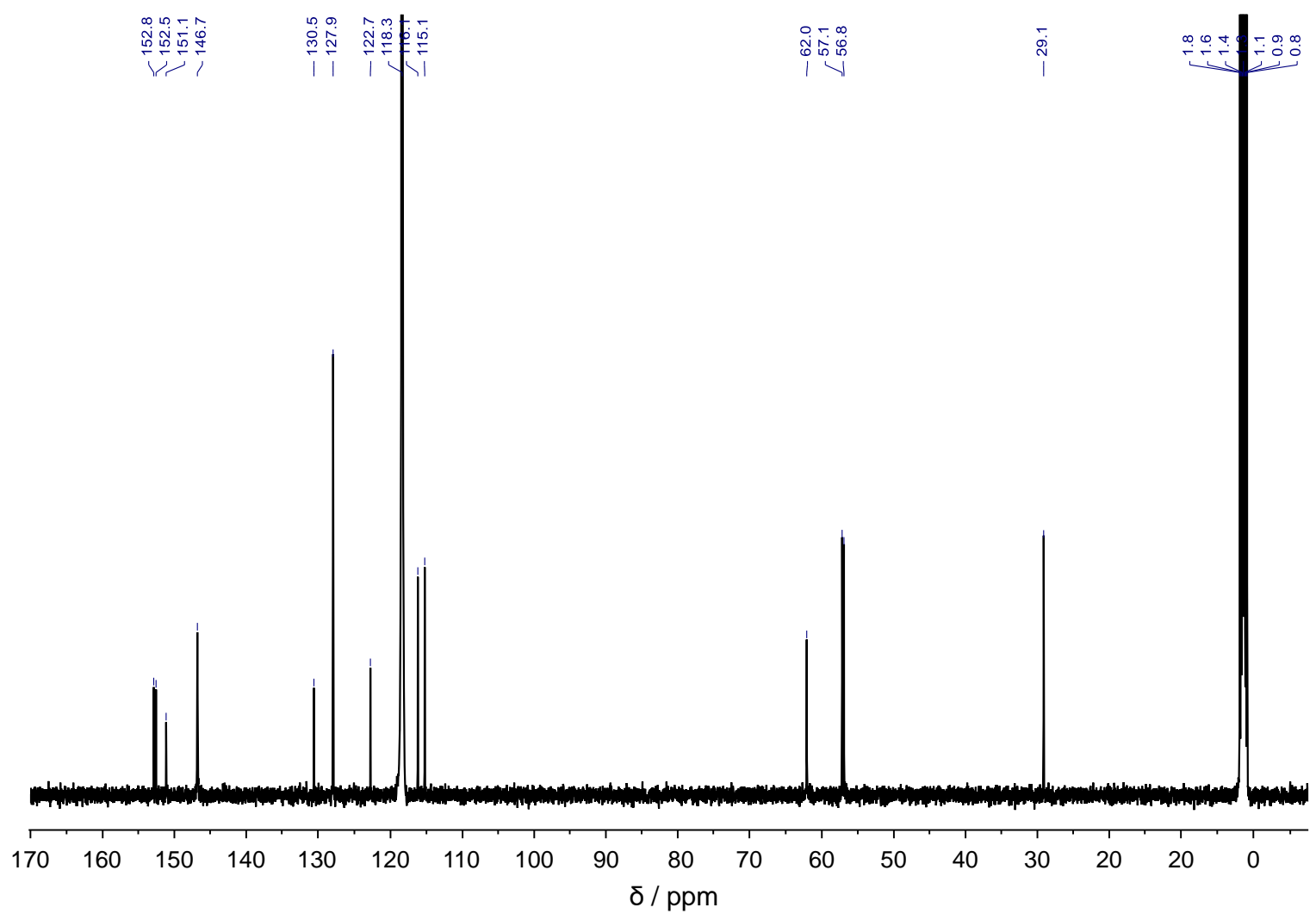

Figure S2. ${ }^{13} \mathrm{C}$ NMR Spectrum of $2 \cdot 2 \mathrm{PF}_{6}$ recorded in $\mathrm{CD}_{3} \mathrm{CN}$ at $293 \mathrm{~K}$
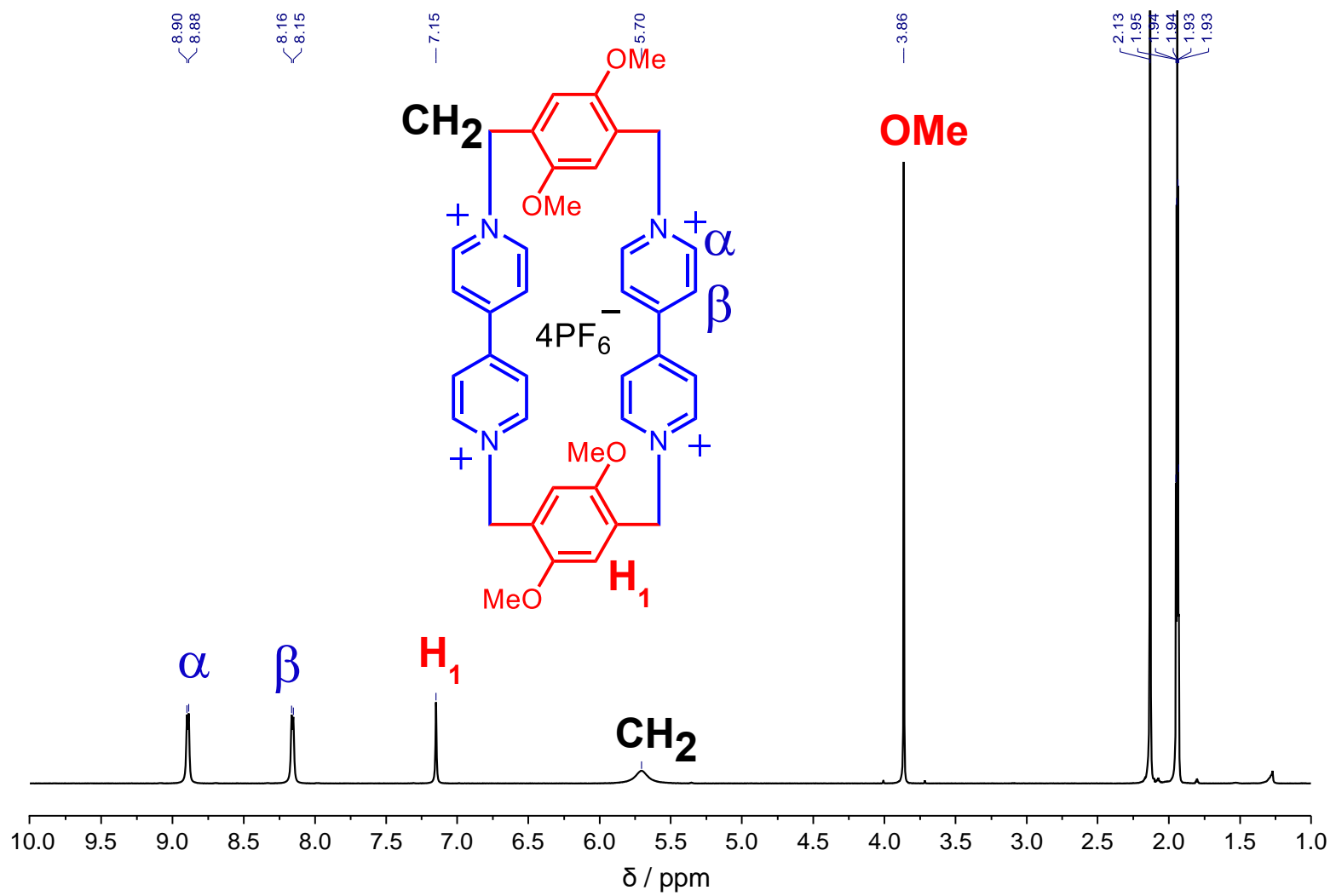

Figure S3. ${ }^{1} \mathrm{H}$ NMR Spectrum of $1 \cdot 4 \mathrm{PF}_{6}$ recorded in $\mathrm{CD}_{3} \mathrm{CN}$ at $293 \mathrm{~K}$ 


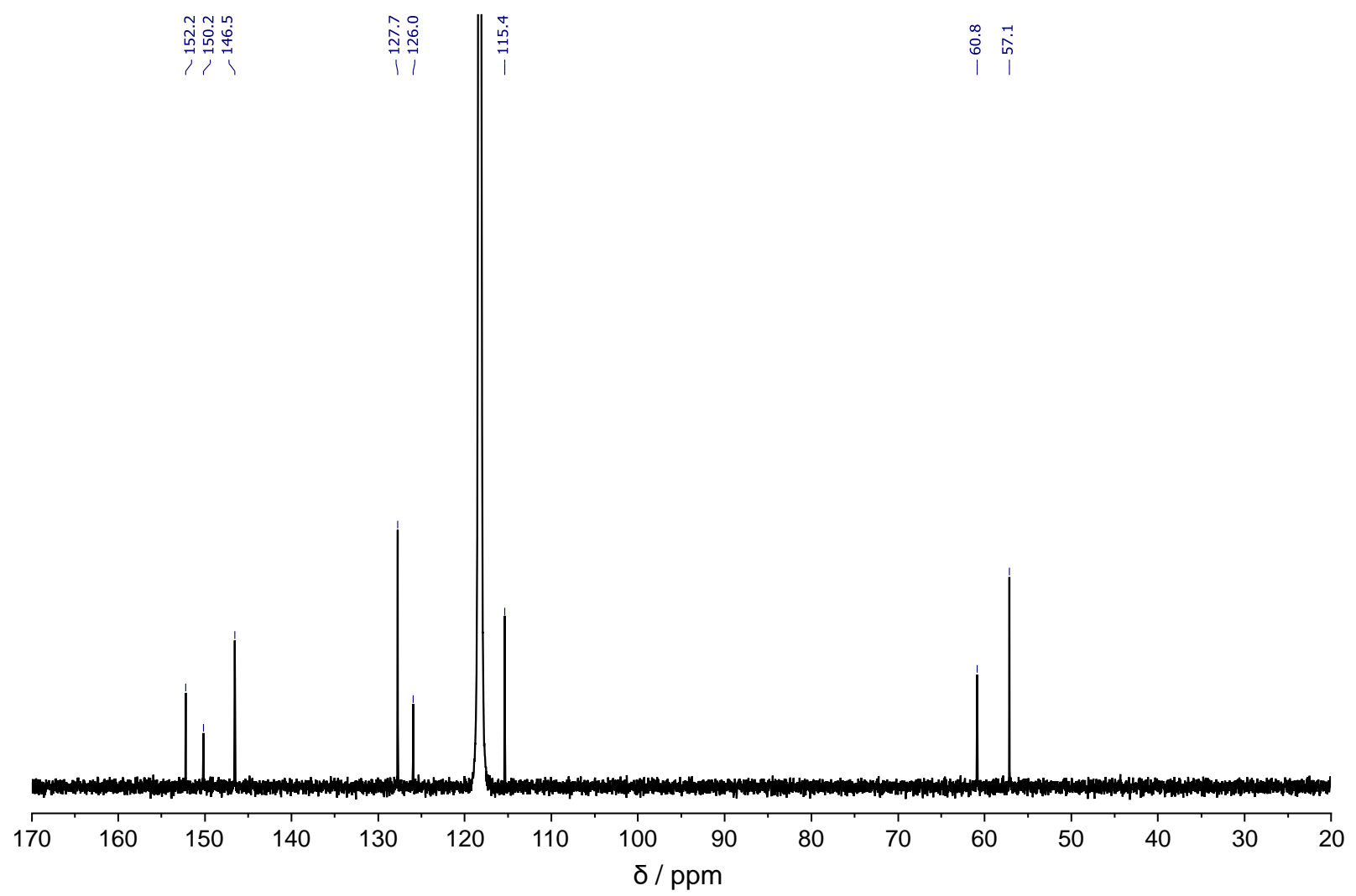

Figure S4. ${ }^{13} \mathrm{C}$ NMR Spectrum of $1 \cdot 4 \mathrm{PF}_{6}$ recorded in $\mathrm{CD}_{3} \mathrm{CN}$ at $293 \mathrm{~K}$

\section{Absorption Spectroscopy}

The $\mathrm{UV}-\mathrm{Vis}$ spectra for $\mathbf{1} \cdot 4 \mathrm{PF}_{6}$ and $\mathbf{1} \cdot 2 \mathrm{PF}_{6}$ depicted in this Section were recorded in dry $\mathrm{MeCN}$ solutions. For determining extinction coefficients $\varepsilon$, five samples of $1.4 \mathrm{PF}_{6}$ were measured at different concentrations and the absorbances obtained for the selected peaks were plotted against the concentrations from which a linear fitting was computed using OriginPro 8.5 SRI b161. The slope obtained from these curve fitting exercises are related to the extinction coefficients.

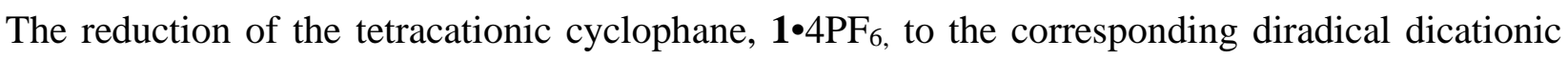
salt, $1 \cdot 2 \mathrm{PF}_{6}$, was carried out by using an excess of $\mathrm{Zn}$ dust in dry and oxygen-free MeCN solution inside a glovebox. The excess of Zn dust was removed by filtration using a PTFE syringe filter with $0.2 \mu \mathrm{m}$ pore size. The UV spectroscopic measurements were subsequently carried out using a cap-sealed UV Quartz cuvette with $1 \mathrm{~cm}$ path-length. 


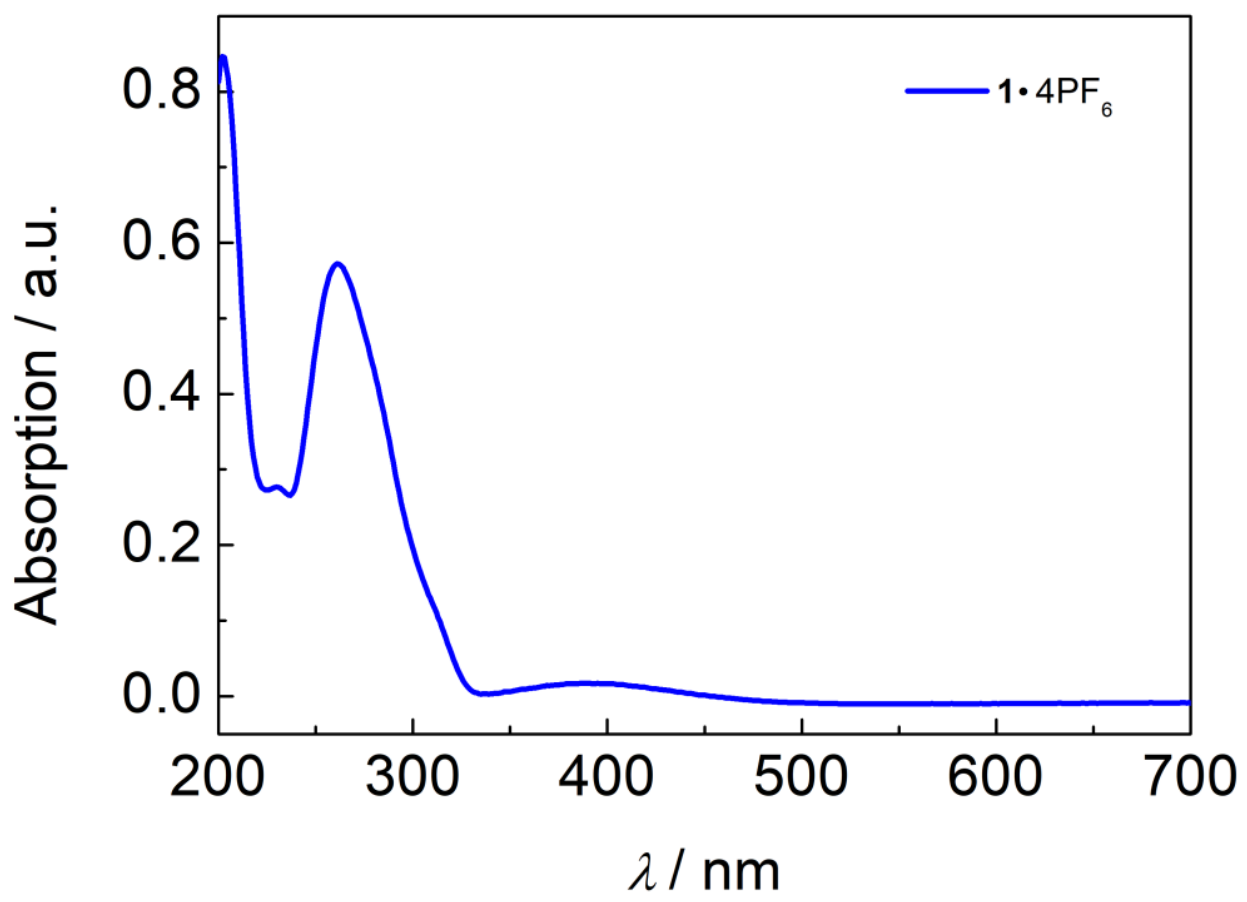

Figure S5. UV-Vis Spectrum of $1.4 \mathrm{PF}_{6}\left(1.23 \times 10^{-5} \mathrm{M}\right)$ recorded in $\mathrm{MeCN}$ at $293 \mathrm{~K}$

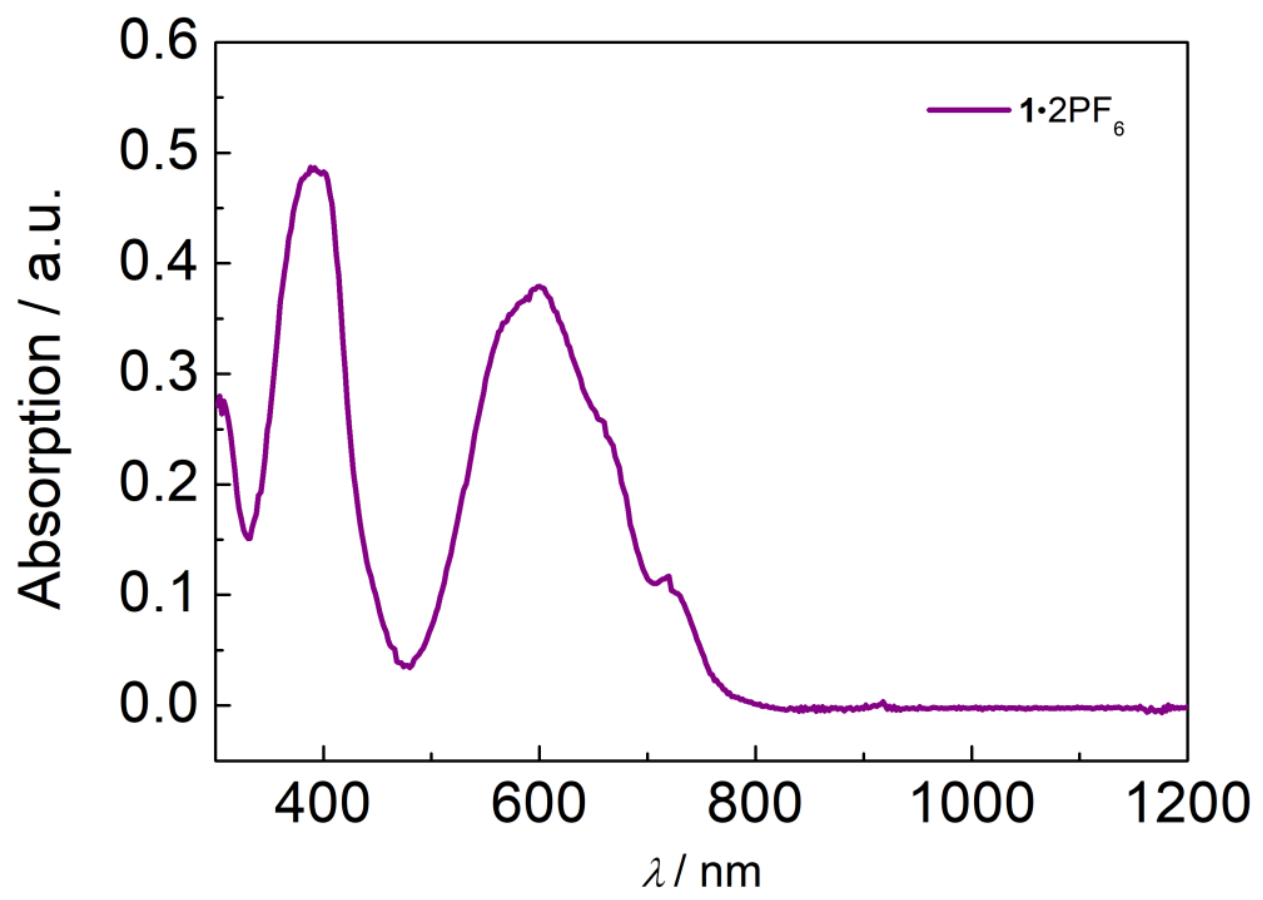

Figure S6. UV-Vis-NIR Spectrum of 1.2PF6 $\left(3.30 \times 10^{-6} \mathrm{M}\right)$ recorded in $\mathrm{MeCN}$ at $293 \mathrm{~K}$ 


\section{Electrochemistry: Cyclic Voltammetry}

$\mathbf{1}^{-4 \mathrm{PF}_{6}}$ was dissolved in an electrolyte solution of $0.1 \mathrm{M} \mathrm{TBAPF}_{6}$ in $\mathrm{MeCN}$. Prior to recording of the cyclic voltammogram, the solution was purged with $\mathrm{N}_{2}$ gas for 5 min and subsequently kept under $\mathrm{O}_{2}$-free conditions to prevent undesired oxidation. A small amount of ferrocene was added to the solution, giving an additional redox wave representing the $\mathrm{Fc} / \mathrm{Fc}^{+}$couple which was used as the internal reference. Host-guest binding between the cyclophane and ferrocene is non-existent. Hence, any interference with the reduction and oxidation of the analyte can be excluded. The redox peaks for $1 \bullet 4 \mathrm{PF}_{6}$ are referenced to the $\mathrm{Fc} / \mathrm{Fc}^{+}$redox couple.

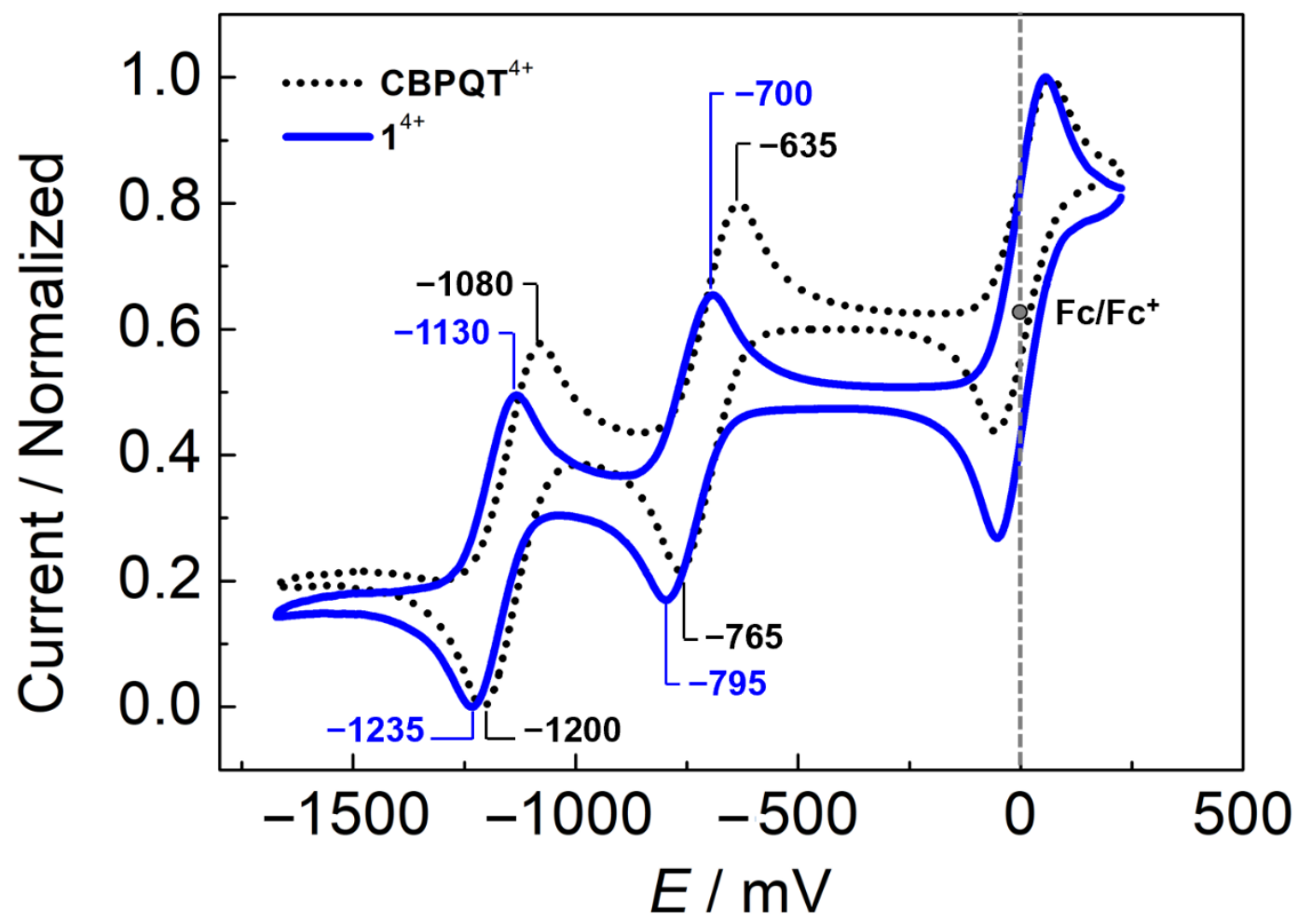

Figure S7. Cyclic voltammogram of $1 \cdot 4 \mathrm{PF}_{6}$ and $\mathrm{CBPQT} \cdot 4 \mathrm{PF}_{6}$ recorded at room temperature at a scan rate of $200 \mathrm{mV} \mathrm{s}^{-1}$ in a $0.1 \mathrm{M} \mathrm{TBAPF}_{6} \mathrm{MeCN}$ solution using a glassy carbon working electrode with $0.071 \mathrm{~cm}^{-2}$ surface area and Pt counter electrode. An organic $\mathrm{Ag} / \mathrm{AgNO}_{3}$ electrode was used as the reference and the peaks are referenced to the $\mathrm{Fc} / \mathrm{Fc}^{+}$couple. 


\section{X-Ray Crystal (Super)structures}

All crystallographic data for the (super)structures reported in this article have been deposited on the Cambridge Crystallographic Data Centre (CCDC) and can be obtained free of charge via www.ccdc.cam.ac.uk/data_request/cif.

In a typical data collection, a suitable crystal was selected and mounted in inert oil and transferred to the cold gas stream of a Bruker Kappa APEX CCD area detector diffractometer. The crystal was kept at $100 \mathrm{~K}$ during data collection. Using Olex $2,{ }^{2}$ the (super)structure was solved with the $\mathrm{XT}^{3}$ structure solution program, employing intrinsic phasing and refined with the $\mathrm{XL}^{4}$ refinement package using least squares minimization. The coordinates of the non-hydrogen atoms were refined anisotropically, while hydrogen atoms were included in the calculated positions. The crystallographic information, structural parameters, and additional refinement details for $\mathbf{1} \bullet^{4} \mathrm{PF}_{6}$,

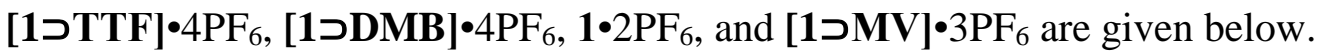

1.4PF6: Method. Crystals were grown by vapor diffusion of ${ }^{i} \mathrm{Pr}_{2} \mathrm{O}$ into a $3 \mathrm{mM}$ solution of $1 \bullet 4 \mathrm{PF}_{6}$ in MeCN. A mixture of yellow and orange crystals was obtained, which corresponded to two separate polymorphs of 1.4PF6. A yellow or orange crystal was immersed in inert oil and subsequently transferred to the cold gas stream of a Kappa Apex 2 diffractometer. The crystal was kept at $100 \mathrm{~K}$ during data collection. Using Olex $2,{ }^{2}$ the structure was solved with the ShelXT ${ }^{3}$ structure solution program using intrinsic phasing and refined with the ShelXL ${ }^{4}$ refinement package using Least Squares minimization. Two different crystal types (polymorphs) were found for $\mathbf{1} \cdot 4 \mathrm{PF}_{6}$, which manifested themselves as either orange-colored cuboids (Figure S8a) or yellow irregular plates (Figure S9a).

X-Ray Crystal Structure Analyses of $1 \mathbf{P P F}$. The cavity sizes, as determined by X-ray crystallographic analysis, are $6.9 \times 10.3 \AA(P 1)$ and $6.7 \times 10.3 \AA\left(P 2_{1} / \mathrm{n}\right)$, respectively, and the torsion angles between the pyridinium units are $28^{\circ}$ and $20^{\circ}$, respectively. The angles between the bipyridinium and the DMP units are found to be $108^{\circ}$ and $107^{\circ}(P \overline{1})$ and $109^{\circ}$ and $108^{\circ}\left(P 2_{1} / \mathrm{n}\right)$. Occupying the space groups $P \overline{1}$ (Figure 3 ) and $P 2_{1} /$ n (Figure 4 ) the cyclophanes show offsetstacking and a slightly offset channel-like stacking, respectively. The cyclophanes in the crystals with space group $P 2{ }_{1} / \mathrm{n}$ also show off-set intermolecular $\pi-\pi$ interactions between two DMP units with $3.3 \AA$, which are not present in the cyclophanes in the crystals with space group $P \overline{1}$. Instead 
the cyclophanes are separated by $3.5 \AA$ without notable $\pi$ - $\pi$ overlap. The $\mathrm{C} \cdot \bullet \mathrm{C}$ distances between the methoxyl groups were found to be 3.8 and $4.3 \AA$ in the space groups $P 2_{1} / \mathrm{n}$ and $P \overline{1}$, respectively. Similar packing resulted from crystals grown in $\mathrm{MeOH}, \mathrm{Me}_{2} \mathrm{CO}$ and $\mathrm{MeCN} / \mathrm{H}_{2} \mathrm{O}$ mixtures. Only one of the two possible isomers with the point group $C_{2 \mathrm{~h}}$ has ever been observed - that is, the DMP units are not exhibiting any disorder during these recrystallization experiments.

\section{(i) Polymorph 1}

Crystal Parameters. $\mathrm{C}_{48} \mathrm{H}_{52} \mathrm{~F}_{24} \mathrm{~N}_{8} \mathrm{O}_{4} \mathrm{P}_{4}$, Monoclinic, space group $P 2{ }_{1} / n$ (no. 14), $a=$ $10.3979(7), b=20.6260(14), c=13.6454(9) \AA, \beta=101.3390(10)^{\circ}, V=2869.5(2) \AA^{3}, Z=2, T=$ $100 \mathrm{~K}, \mu(\mathrm{MoK} \alpha)=0.26 \mathrm{~mm}^{-1}$, Dcalc $=1.60 \mathrm{~g} / \mathrm{cm}^{3}, 74789$ reflections measured $\left(3.63^{\circ} \leq 2 \Theta \leq\right.$ $\left.61.06^{\circ}\right), 8763$ unique $\left(R_{\text {int }}=0.04, R_{\text {sigma }}=0.02\right)$ which were used in all calculations. The final $R_{1}$ value was $0.04(I>2 \sigma(I))$ and $w R_{2}$ was 0.10 (all data). No disorder was observed in the sample; no restraints were used in the refinement. CCDC 1914905.

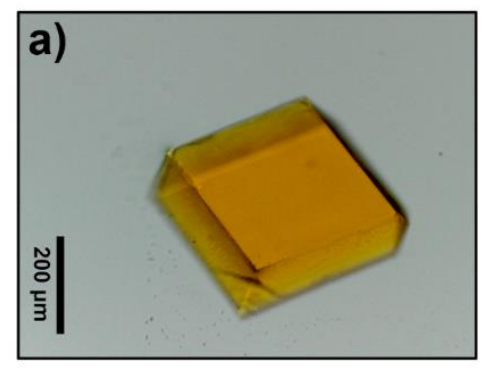

b)

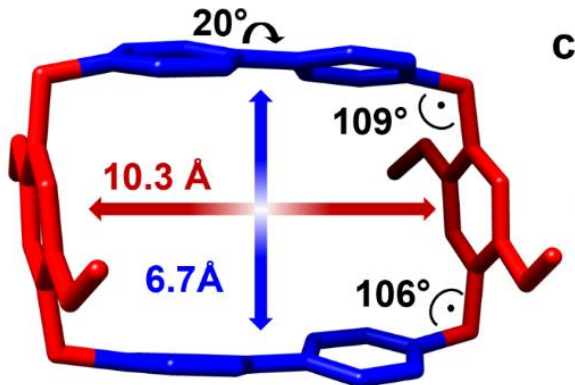

c)

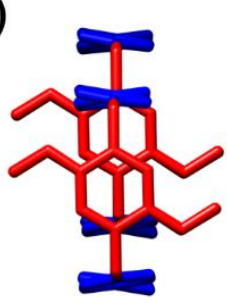

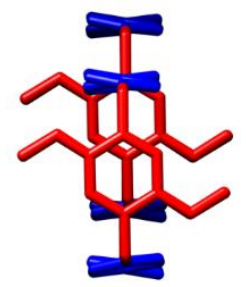

d)

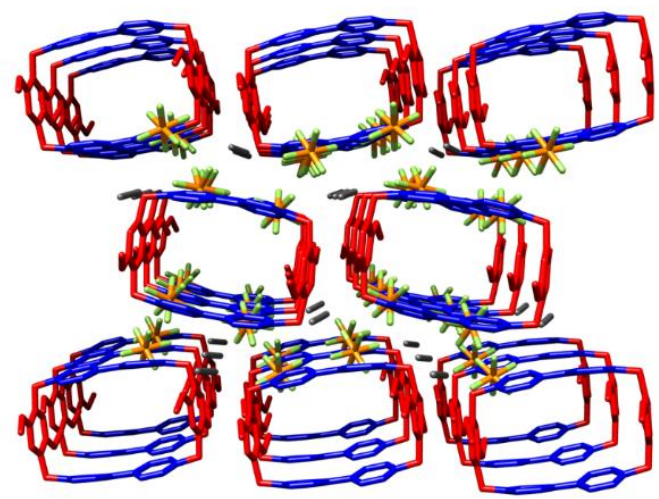

e)

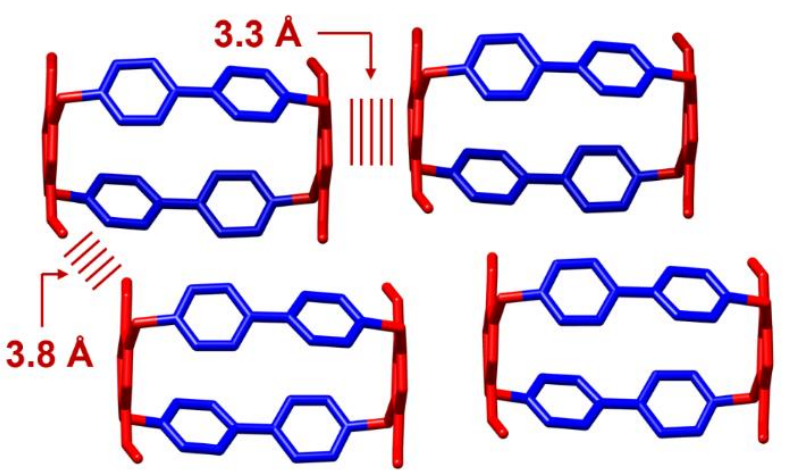

Figure S8. Tubular representations of the solid-state (super)structure of $1.4 \mathrm{PF}_{6}$ with point group $P 2_{1} / n$ : a) Microscope photograph of a single crystal. b) Plan-view of $1^{4+}$ belonging to the space group $P 2 / n$, illustrating the size and angles of a single cyclophane. c) Side-on view of two cyclophanes illustrating offset m-overlap between DMP units. d) Offset-stacking of cyclophanes in the superstructure. e) Angled planar view of four cyclophanes visualizing offset $[\pi-\pi]$ separation between DMP units and Van der Waals separation between methoxyl groups. In all pictures, except in the case of d), $\mathrm{PF}_{6}{ }^{-}$counterions are not shown for the sake of clarity. 


\section{(i) Polymorph 2}

Crystal Parameters. $\mathrm{C}_{52} \mathrm{H}_{58} \mathrm{~F}_{24} \mathrm{~N}_{10} \mathrm{O}_{4} \mathrm{P}_{4}$, Triclinic, space group $P \overline{1}$ (no. 2), $a=10.9093(8) \AA$, $b=11.8788(9) \AA, c=14.0160(11) \AA, \alpha=112.990(2)^{\circ}, \beta=93.419(2)^{\circ}, \gamma=105.009(2)^{\circ}, V=$ 1588.4(2) $\AA^{3}, Z=1, T=99.99 \mathrm{~K}, \mu(\mathrm{MoK} \alpha)=0.242 \mathrm{~mm}^{-1}$, Dcalc $=1.534 \mathrm{~g} / \mathrm{cm}^{3}, 57137$ reflections measured $\left(3.21^{\circ} \leq 2 \Theta \leq 59.384^{\circ}\right), 8832$ unique $\left(R_{\text {int }}=0.0264, R_{\text {sigma }}=0.0176\right)$ which were used in all calculations. The final $R_{1}$ was $0.0354(I>2 \sigma(I))$ and $w R_{2}$ was 0.0977 (all data). CCDC 1914882 .

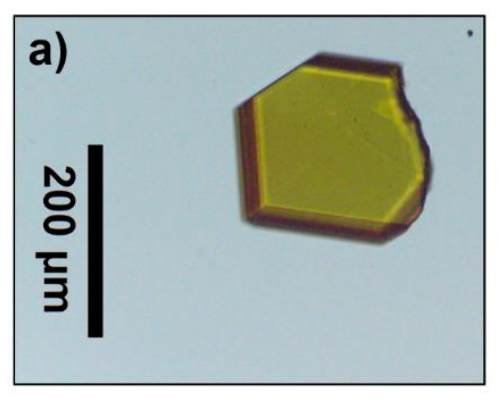

b)

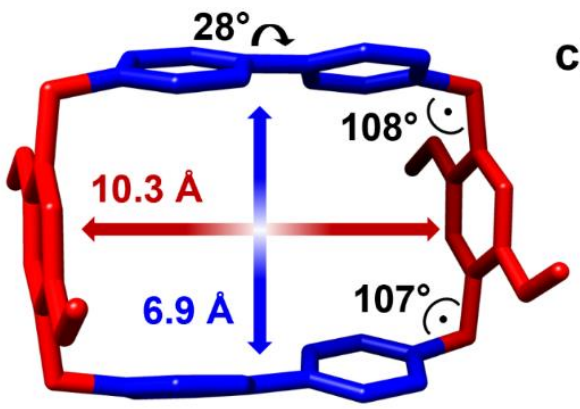

c)

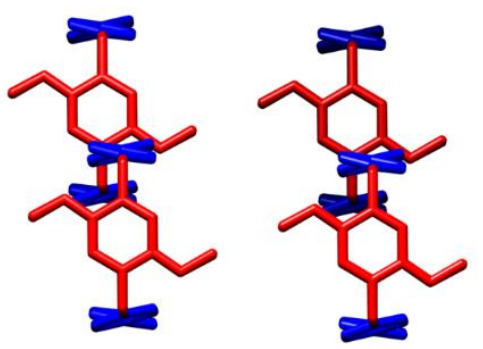

d)

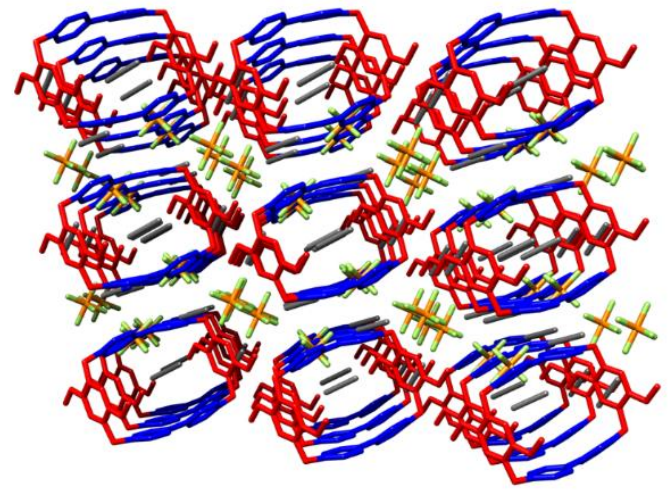

e)

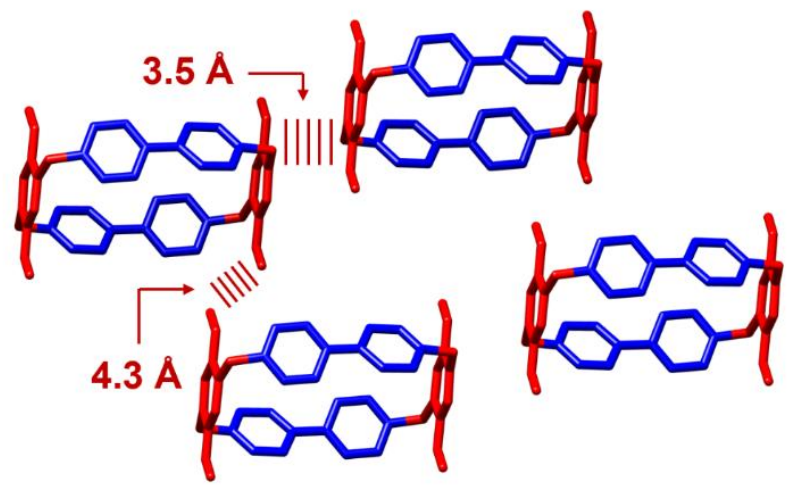

Figure S9. Tubular representations of the solid-state (super)structure of $1 \cdot 4 \mathrm{PF}_{6}$ with point group $P \overline{1}$ : a) Microscope photograph of a single crystal. b) Plan-view of $1^{4+}$ belonging to the space group $P \overline{1}$, illustrating the size and angles of a single cyclophane. c) Side-on view of four cyclophanes illustrating offset m-overlap between DMP units. d) Offset-stacking of cyclophanes in the superstructure. e) Angled planar view of four cyclophanes visualizing offset $[\pi-\pi]$ separation between DMP units and Van der Waals separation between methoxy groups. In all pictures, except in the case of d), $\mathrm{PF}_{6}{ }^{-}$counterions are not shown for the sake of clarity.

\section{X-Ray Crystal Structure Analyses of Host-Guest Complexes [1つTTF]•4PF6 and} [1دDMP]•4PF 6. We investigated the complexation of $1 \mathbf{1}^{-4 \mathrm{PF}_{6}}$ with tetrathiafulvalene (TTF) and dimethoxybenzene (DMB) in the solid state by X-ray crystallography, employing crystals obtained 
from the slow diffusion of ${ }^{i} \operatorname{Pr}_{2} \mathrm{O}$ into a mixture of $1 \bullet 4 \mathrm{PF}_{6}$ and either TTF or DMB in MeCN yielding green and red-colored crystals, respectively. The superstructure of $[\mathbf{1} \supset \mathbf{T T F}]^{4+}$ reveals (Figure S10) a channel-like stacking of the tetracationic cyclophane. In comparison with $\mathbf{1}^{\mathbf{4 +}}$, the incorporation of TTF increases the cavity width up to $7.0 \AA$ and simultaneously reduces its length down to 10.2 $\AA$. The torsion angles between the planes of the pyridinium rings are reduced, exhibiting an angle of $11.5^{\circ}$ on both sides of the tetracationic cyclophane. A similar solid-state superstructure with the same space group was observed (Figure S11) for $[\mathbf{1} \supset \mathbf{D M B}]^{4+}$. The cavity size of $7.0 \times 10.1 \AA$ is similar to that of $[\mathbf{1} \supset \mathbf{T T F}]^{4+}$. The torsion angle between the pyridinium rings in the bipyridinium units was found to be $17^{\circ}$, angles which lie between the angles observed for $[\mathbf{1} \mathbf{D M P}]^{4+}$ and those for the cyclophane itself. In conclusion, we found that the host-guest complexes $[\mathbf{1} \supset \mathbf{T T F}]^{4+}$ and

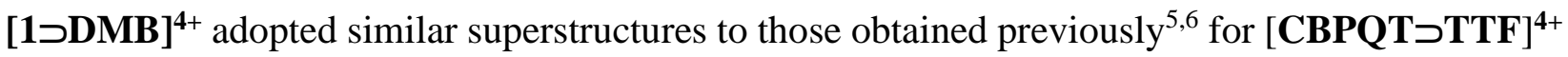
and $[\mathbf{C B P Q T} \supset \mathbf{D M B}]^{4+}$ and that there is little evidence for any interactions between the guests and the methoxy groups present in the cyclophanes in both cases.

$[\mathbf{1} \mathrm{TTF}] \bullet 4 \mathrm{PF}_{6}:$ Method. Crystals of $[\mathbf{1} \supset \mathbf{T T F}] \bullet 4 \mathrm{PF}_{6}$ bearing a green-colored appearance were obtained using the samples from titration experiments containing an excess of TTF in $\mathrm{CD}_{3} \mathrm{CN}$ solution. Crystal Parameters. $\mathrm{C}_{25} \mathrm{H}_{25} \mathrm{~F}_{12} \mathrm{~N}_{3} \mathrm{O}_{2} \mathrm{P}_{2} \mathrm{~S}_{2}$, Triclinic, space group $P \overline{1}$ (no. 2), $a=$ 10.4509(4), $b=12.2972(4), c=13.7176(5), \alpha=64.875(2), \beta=77.838(2), \gamma=65.854(2), V=$ 1455.03(10) $\AA^{3}, Z=2, T=100 \mathrm{~K}, \mu(\mathrm{MoK} \alpha)=0.403 \mathrm{~mm}^{-1}$, Dcalc $=1.720 \mathrm{~g} / \mathrm{cm}^{3}, \quad 23652$ reflections measured $\left(3.282^{\circ} \leq 2 \Theta \leq 56.39^{\circ}\right), 7081$ unique $\left(R_{\text {int }}=0.0423, R_{\text {sigma }}=0.0481\right)$ which were used in all calculations. The final $R_{1}$ was $0.0429(I>2 \sigma(I))$ and $w R_{2}$ was 0.1064 (all data). CCDC 1914886. 
a)

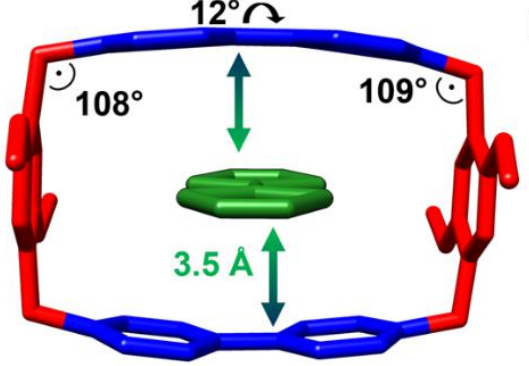

d)

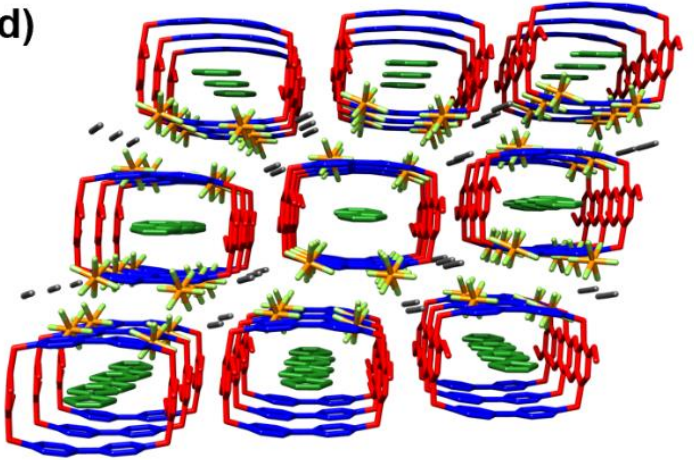

b)

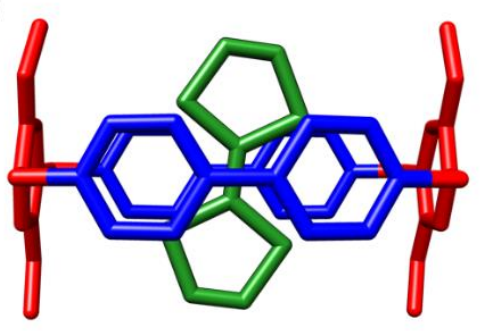

c)

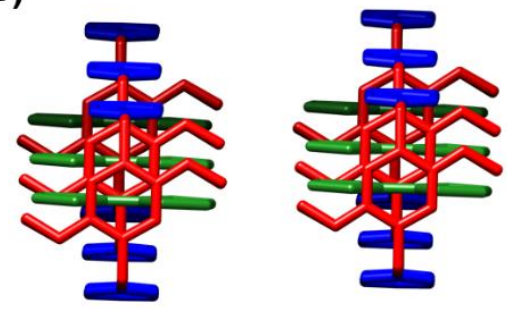

e)

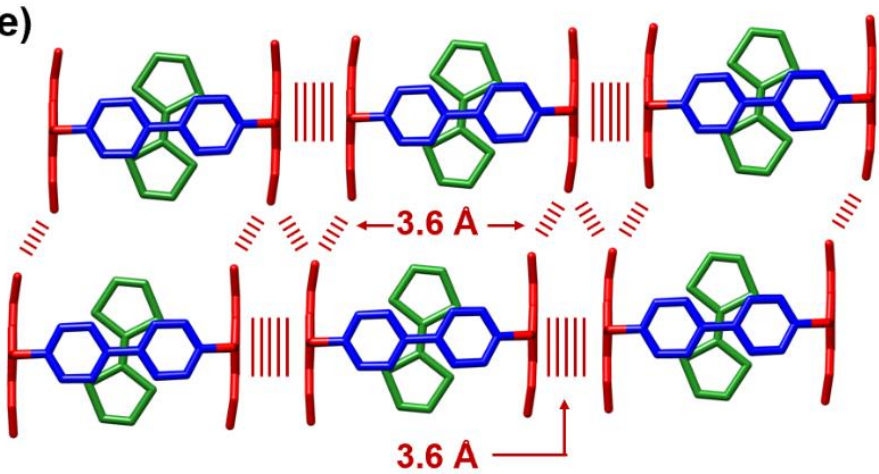

Figure S10. a) Tubular representations of the solid-state (super)superstructure of [1دTTF] ${ }^{4+}$ illustrating the cavity size and bond angles for the tetracationic cyclophane. b) Plan-view of the 1:1 complex, showing offset positioning of TTF molecule inside the cavity. c) Side-on view of six host-guest complexes, indicating offset separations between the DMP units. d) Superstructure of the 1:1 complex including $\mathrm{PF}_{6}{ }^{-}$counterions and MeCN solvent molecules. e) Plan-view of six complexes, illustrating distances between the DMP units. In all pictures, except in the case of $d$ ), $\mathrm{PF}_{6}{ }^{-}$counterions are not shown for the sake of clarity.

$[1 \supset \mathrm{DMB}] \bullet 4 \mathrm{PF}_{6}$ : Method. Crystals of $[\mathbf{1} \mathrm{DDMB}] \bullet 4 \mathrm{PF}_{6}$, bearing a red-colored appearance, were obtained using the samples from titration experiments containing an excess of $\mathbf{D M B}$ in $\mathrm{CD}_{3} \mathrm{CN}$ solution. Crystal Parameters. for $\mathrm{C}_{52} \mathrm{H}_{56} \mathrm{~F}_{24} \mathrm{~N}_{6} \mathrm{O}_{6} \mathrm{P}_{4}$, Triclinic, space group $P \overline{1}$ (no. 2), $a=$ 10.3883(5), $b=10.9508(5), c=13.4312(7), \alpha=84.113(2), \beta=86.835(2), \gamma=74.908(2)$, $V=1466.81(12) \AA^{3}, Z=1, T=100 \mathrm{~K}, \mu(\mathrm{MoK} \alpha)=0.261 \mathrm{~mm}^{-1}$, Dcalc $=1.631 \mathrm{~g} / \mathrm{cm}^{3}, 22824$ reflections measured $\left(3.05^{\circ} \leq 2 \Theta \leq 56.024^{\circ}\right), 7051$ unique $\left(R_{\text {int }}=0.0358, R_{\text {sigma }}=0.0415\right)$ which were used in all calculations. The final $R_{1}$ was $0.0474(I>2 \sigma(I))$ and $w R_{2}$ was 0.1202 (all data). CCDC 1914883. 
a)

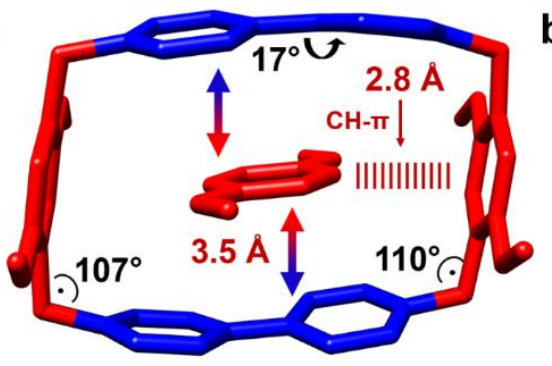

b)

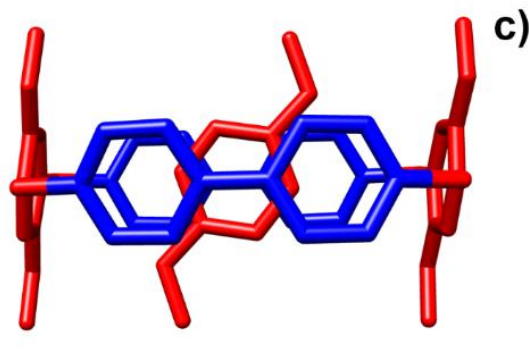

c)

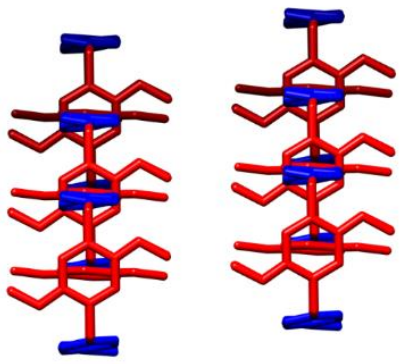

d)

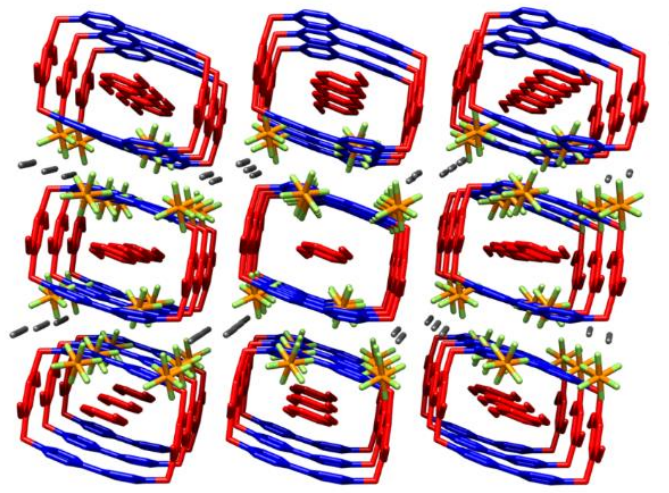

e)

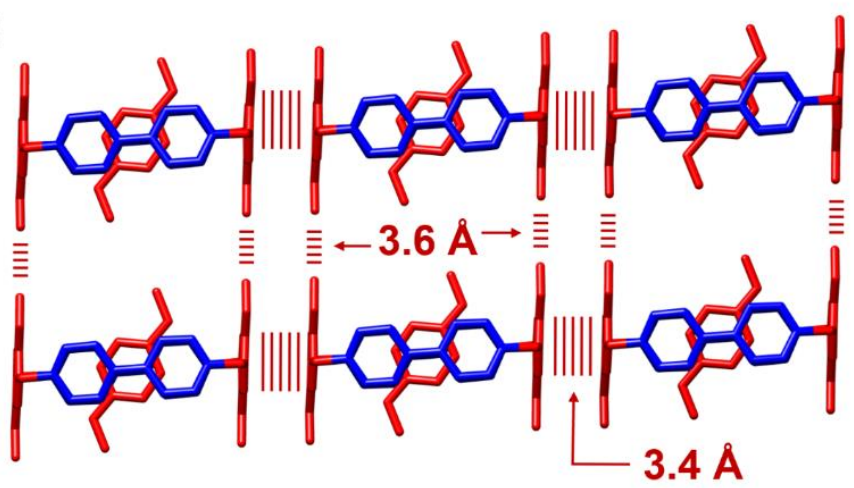

Figure S11. a) Tubular representations of the solid-state (super)structure of [1DDMB] $]^{4+}$ illustrating the cavity size and angles. b) Plan-view depicting the DMB guest molecule located offset inside the cavity. c) Side-on view of six 1:1 complexes indicating offset separations between the DMP units. d) Superstructure of complex including $\mathrm{PF}_{6}{ }^{-}$counterions and $\mathrm{MeCN}$ solvent molecules. e) Plan-view of six 1:1 complexes, illustrating the distances between the DMP units in neighboring 1:1 complexes. In all pictures, except in the case of d), $\mathrm{PF}_{6}{ }^{-}$counterions are not shown for the sake of clarity.

1•2 $\mathrm{PF}_{6}$ : Method. Dark blue crystals of $1 \cdot 2 \mathrm{PF}_{6}$ were obtained by vapor diffusion of ${ }^{i} \mathrm{Pr}_{2} \mathrm{O}$ into a solution of $1 \cdot 2 \mathrm{PF}_{6}$ in $\mathrm{MeCN}$ which was prepared by reduction of $1 \bullet 4 \mathrm{PF}_{6}$ using $\mathrm{Zn}$ dust in $\mathrm{MeCN}$ inside a glovebox. No disorder was observed in the sample; no restraints were used in the refinement. Crystal Parameters. $\mathrm{C}_{40} \mathrm{H}_{40} \mathrm{~F}_{12} \mathrm{~N}_{4} \mathrm{O}_{4} \mathrm{P}_{2}$, Monoclinic, space group $C 2 / c$ (no. 15), $a=$ $12.155(2), b=23.664(5), c=20.711(4), \beta=90.006(3), V=5957(2) \AA^{3}, Z=4, T=100.0 \mathrm{~K}$, $\mu(\mathrm{MoK} \alpha)=0.143 \mathrm{~mm}^{-1}$, Dcalc $=1.038 \mathrm{~g} / \mathrm{cm}^{3}, 36620$ reflections measured $\left(3.768^{\circ} \leq 2 \Theta \leq\right.$ $\left.50.046^{\circ}\right), 5188$ unique $\left(R_{\text {int }}=0.0451, R_{\text {sigma }}=0.0282\right)$ which were used in all calculations. The final $R_{1}$ was $0.1412(I>2 \sigma(I))$ and $w R_{2}$ was 0.4331 (all data). CCDC 1914887. 
Refinement Details. The two 1,4-dimethoxy-2,5-xylenyl units within $\mathbf{1}^{2(\cdot+)}$ were found to be disordered and have been modeled over two sites with a 50\% occupancy for each site. The solventmasking procedure, as implemented in Olex2, was used to remove the electronic contributions of heavily disordered solvent molecules from the refinement. Since the exact solvent content is not known, only the atoms used in the refinement model are reported here in the formula. Total solvent accessible volume / cell $=608.05 \AA^{3}[10.2 \%]$

[د $\mathbf{1} \mathbf{M V ]} \cdot 3 \mathrm{PF}_{6}:$ Method. $[\mathbf{1} \supset \mathbf{M V}] \cdot 3 \mathrm{PF}_{6}$, was recrystallized by vapor diffusion of oxygen-free ${ }^{i} \mathrm{Pr}_{2} \mathrm{O}$ into a freeze-dried $\mathrm{MeCN}$ solution obtained after the reduction of a 1:1 ratio mixture of $\mathbf{1}^{\bullet} 4 \mathrm{PF}_{6}$ and $\mathbf{M V} \cdot 2 \mathrm{PF}_{6}$ using $\mathrm{Zn}$ dust. The reduction and recrystallization was carried out inside a glovebox under an atmosphere of $\mathrm{N}_{2}$. Crystal Parameters. $\mathrm{C}_{60} \mathrm{H}_{66} \mathrm{~F}_{18} \mathrm{~N}_{10} \mathrm{O}_{4} \mathrm{P}_{3}(M=1426.13 \mathrm{~g} / \mathrm{mol})$ : triclinic, space group $P \overline{1}$ (no. 2), $a=12.1780(7), b=12.6271(7), c=12.8582(7), \alpha=112.345(3)$, $\beta=98.076(3), \gamma=113.601(3), V=1572.70(16) \AA^{3}, Z=1, T=100.01 \mathrm{~K}, \quad \mu(\mathrm{MoK} \alpha)=$ $0.204 \mathrm{~mm}^{-1}$, Dcalc $=1.506 \mathrm{~g} / \mathrm{cm}^{3}, 29448$ reflections measured $\left(3.89^{\circ} \leq 2 \Theta \leq 50.216^{\circ}\right), 5575$ unique $\left(R_{\text {int }}=0.0302, R_{\text {sigma }}=0.0291\right)$ which were used in all calculations. The final $R_{1}$ was 0.0721 $(I>2 \sigma(I))$ and $w R_{2}$ was 0.1942 (all data). CCDC 1914888. Refinement Details. The solventmasking procedure, as implemented in Olex2, was used to remove the electronic contributions of heavily disordered solvent molecules from the refinement. Since the exact solvent content is not known, only the atoms used in the refinement model are reported here in the formula. Total solvent accessible volume / cell $=50.94 \AA^{3}[3.2 \%]$. 


\section{Titration Experiments}

\section{Binding studies between $1 \bullet 4 \mathrm{PF}_{6}$ and neutral guests}

We took note of the fact that the dimensions of $\mathbf{1}^{\mathbf{4 +}}$ are very similar to those of the parent $\mathbf{C B P Q T}{ }^{\mathbf{4}}$. As such, we anticipated that $\mathbf{1}^{\mathbf{4}+}$ should be able to bind planar aromatic guest molecules on account of noncovalent bonding interactions, but with modulated binding affinities because of the presence of the four methoxy substituents on the $p$-phenylene pillars. We carried out binding studies with $\mathbf{1}^{\mathbf{4}+}$ by assessing its binding affinity for planar neutral molecules. In an attempt to make meaningful comparisons with CBPQT $^{4+}$, tetrathiafulvalene ${ }^{5}$ (TTF) and 1,4-dimethoxybenzene ${ }^{6}(\mathbf{D M B})$ were selected as suitable guests.

${ }^{1} \mathrm{H}$ NMR Titrations were performed by additions of either TTF $(50 \mathrm{mM})$ or DMB $(5 \mathrm{M})$ in a solution of $1{ }^{-4} \mathrm{PF}_{6}(0.5 \mathrm{mM})$ in $\mathrm{CD}_{3} \mathrm{CN}$ to a $0.5 \mathrm{mM}$ solution of $1 \bullet 4 \mathrm{PF}_{6}$ in $\mathrm{CD}_{3} \mathrm{CN}$. Spectra were recorded on either a $400 \mathrm{MHz}$ Agilent DD MR-400 spectrometer or Bruker Avance III $500 \mathrm{MHz}$ spectrometer equipped with a DCH CryoProbe and calibrated to the residual solvent peak in $\mathrm{CD}_{3} \mathrm{CN}(\delta=1.94 \mathrm{ppm})$. Stacked spectra were generated using MestreNova v11.0.4. Changes in chemical shift upon the addition of guests were fitted to a 1:1 binding model using an Excel spreadsheet, 14allMaster.xls, developed by Professor Christopher A Hunter (University of Cambridge).

The addition of both TTF and DMB (Figure S12) resulted in significant shifts in the $\delta$ values of selected host protons, as expected for complexation and the data were fitted to a 1:1 binding isotherm. $^{7}$ The binding affinities between $\mathbf{1}^{4+}$ and both DMB and TTF were calculated to be $26 \pm 1 \mathrm{M}^{-1}$ and $9450 \pm 1290 \mathrm{M}^{-1}$, respectively. The values obtained were similar in magnitude to those reported ${ }^{5,6}$ previously for CBPQT•4PF6. 
This observation suggests that the introduction of electron-donating methoxy substituents on the $p$-phenylene pillars have little effect on the ability of the electron deficient cyclophane to bind electron rich substrates, most likely because of the strong electrostatic cavity forces dominating over external interactions. Inclusion of a substrate inside the cavity of $\mathbf{1}^{\mathbf{4}+}$ in solution restricts the rotation of the DMP pillars, resulting in separation of the broad singlet corresponding to the methylene groups into two separate peaks representing the resonances for the diastereotopic protons (see Figures S12-S14). Based on solution studies no preferred geometry for the DMP pillars to adopt relative to the guest could be determined since it is possible that the chemical shifts for the methylene groups of the two possible isomers, $C_{2 \mathrm{~h}}$ and $D_{2}$, are identical.
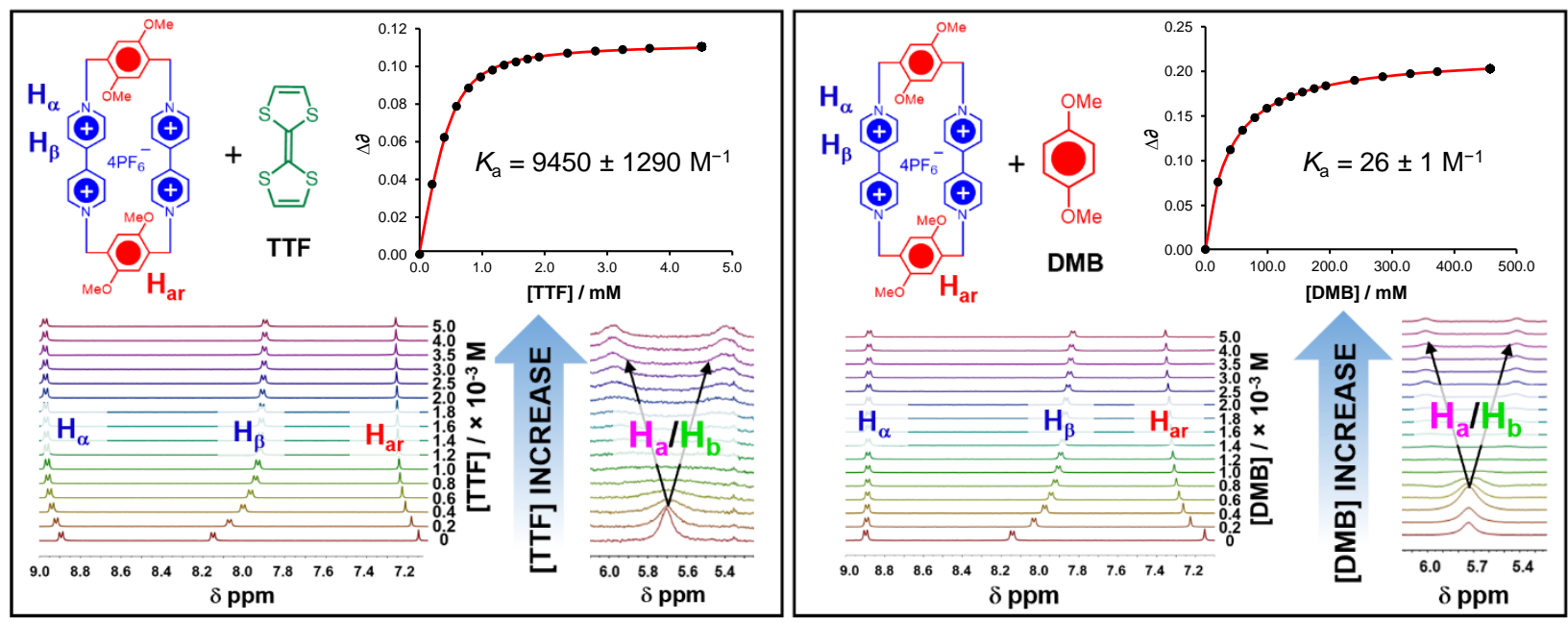

Figure S12. Complexation of TTF (left) and DMB (right) by $\mathbf{1}^{4+}$. Top right of each box: Binding curve fitted to a 1:1 binding isotherm. Also see spectra and isotherms below. ${ }^{1} \mathrm{H}$ NMR Spectra recorded in $\mathrm{CD}_{3} \mathrm{CN}$ show changes in chemical shifts upon increasing the concentration of TTF or DMB. At higher substrate concentrations, the $\mathrm{AB}$ system for the methylene protons splits into two resonances reflecting the generation of the two diastereotopic protons. 
a)

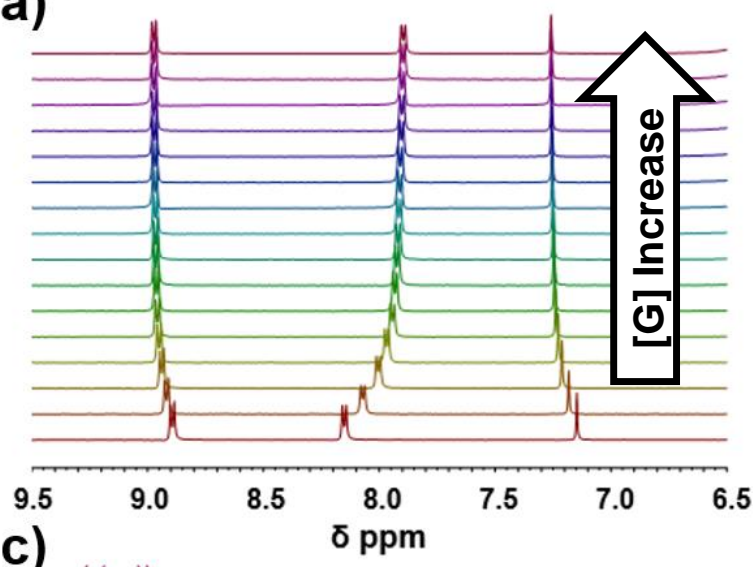

c)

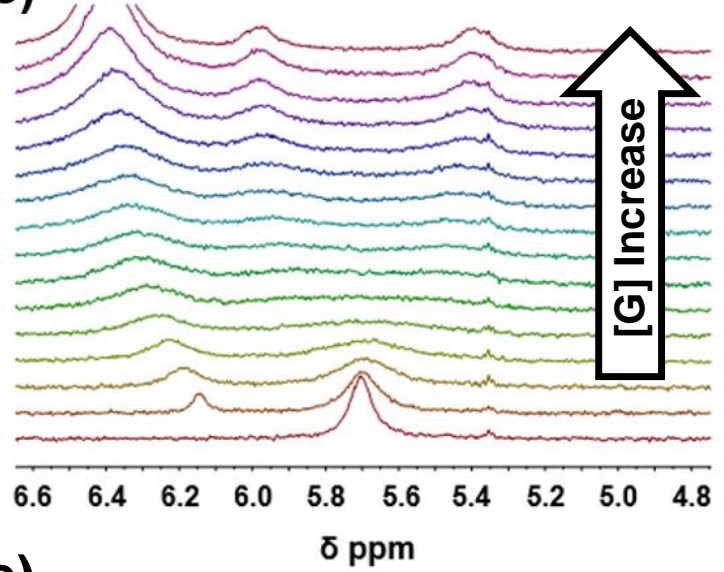

e)

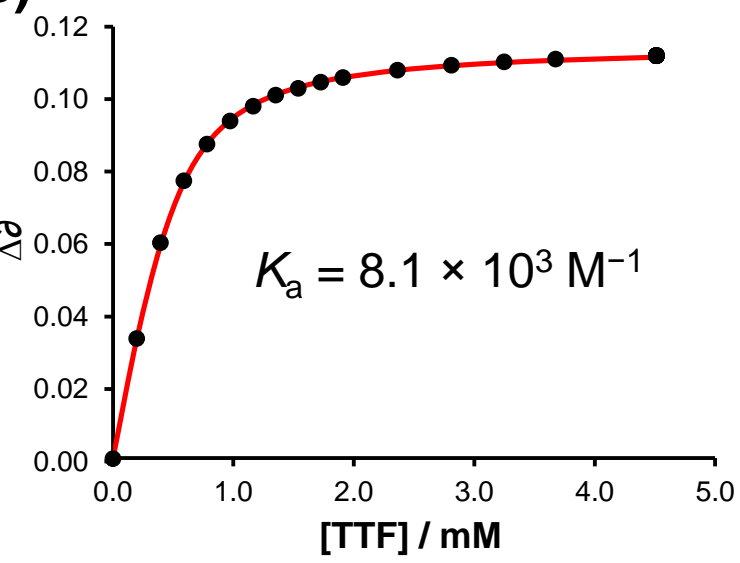

b)

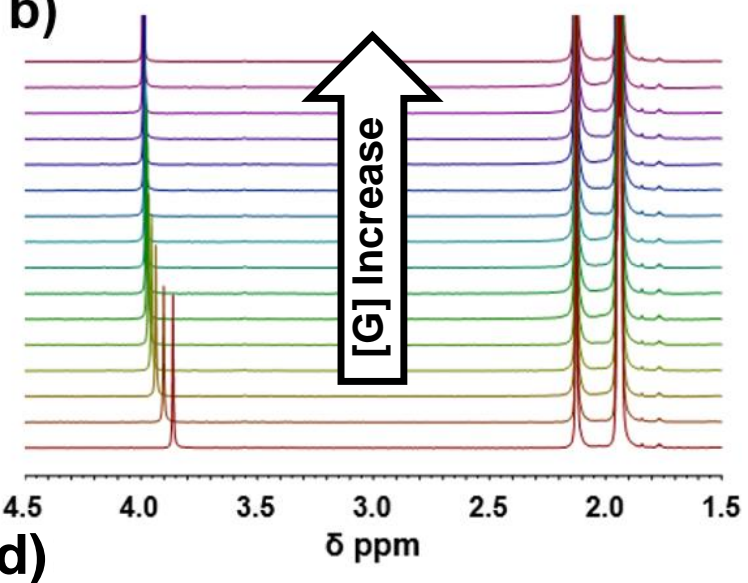

d)

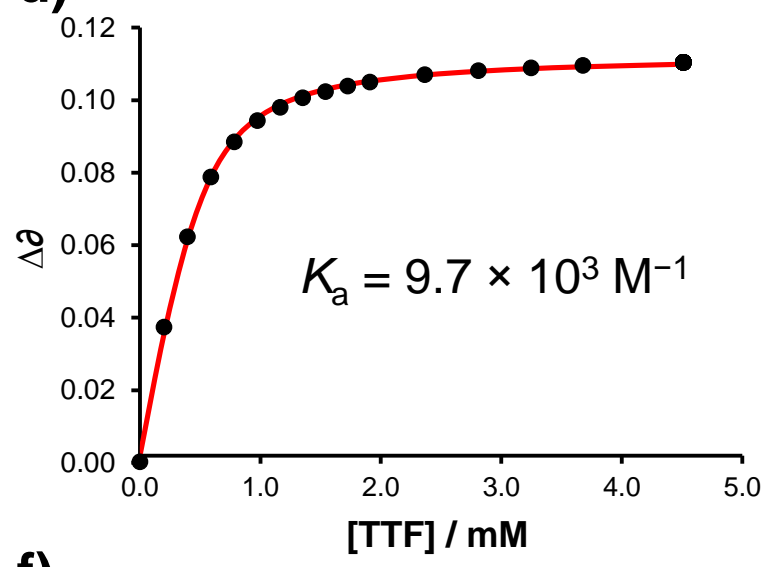

f)

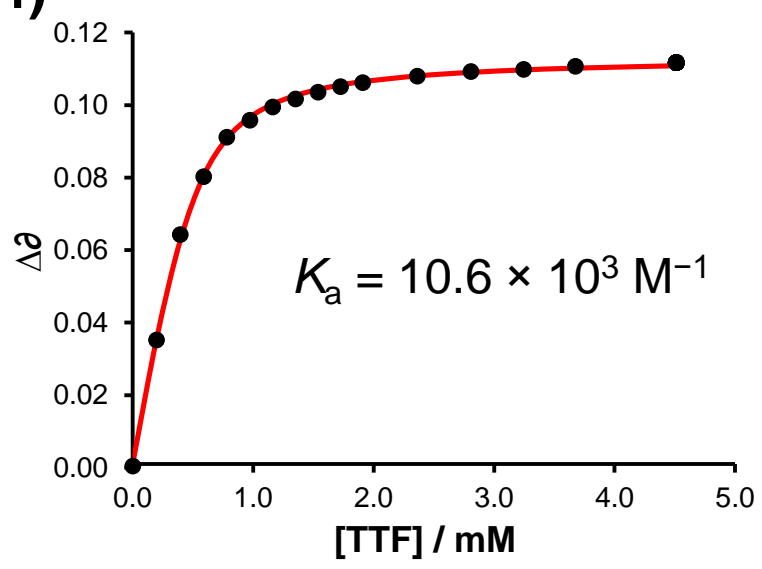

Figure S13. ${ }^{1} \mathrm{H}$ NMR titration of $1{ }^{\circ} 4 \mathrm{PF}_{6}$ with $\mathrm{TTF}$ in $\mathrm{CD}_{3} \mathrm{CN}$ at room temperature. a) Downfield portion of the ${ }^{1} \mathrm{H}$ NMR spectra showing the shift of the resonances for the protons on the bipyridinium units and the resonances for the aromatic protons of the DMP units upon addition of TTF. b) Upfield portion of the ${ }^{1} \mathrm{H}$ NMR spectra showing the shift of the resonances for the methoxy protons upon addition of TTF. c) Central portion of the ${ }^{1} \mathrm{H}$ NMR spectra depicting the separation of the broad peak for the AB system for the methylene protons into two broad peaks. In d), e) and f) binding curves from repeated titration experiments are shown representing the change of the chemical shift for the proton at $\delta=7.15 \mathrm{ppm}$ when $[G]=0$ ) against the substrate concentration based on a 1:1 binding isotherm. 
a)

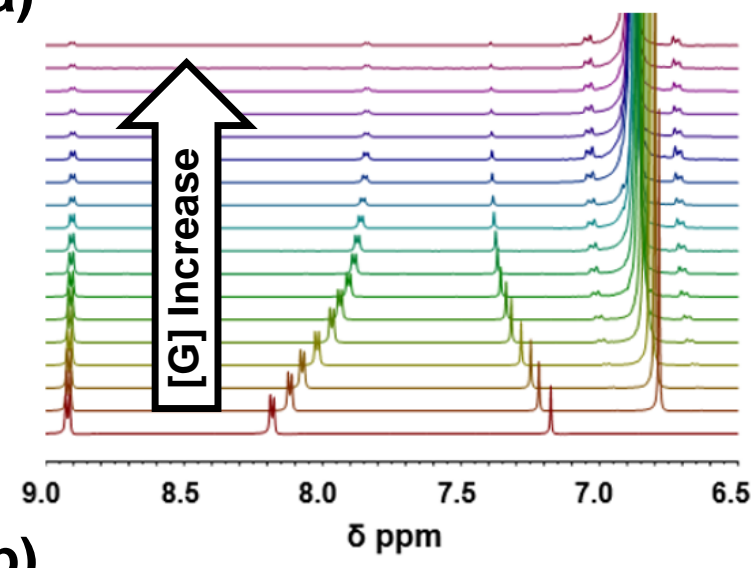

b)

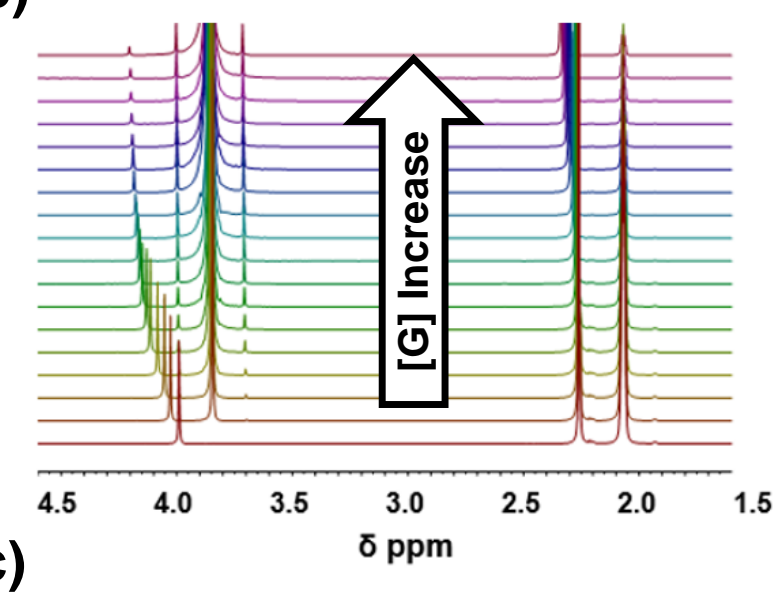

c)

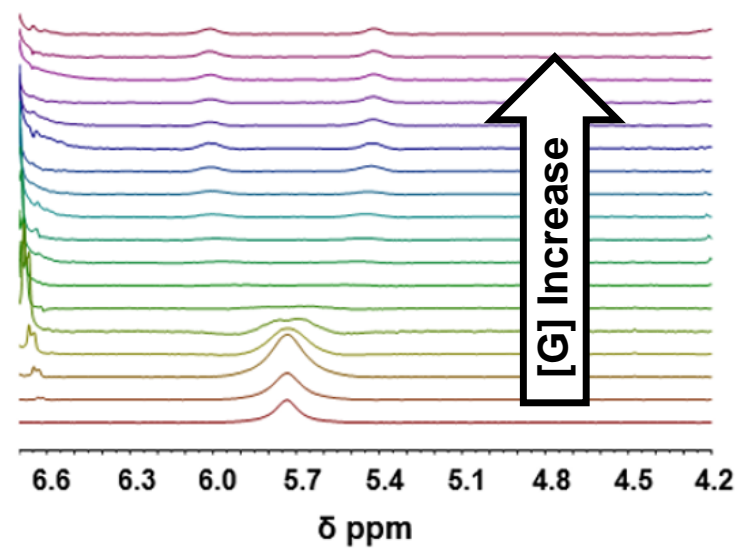

d)

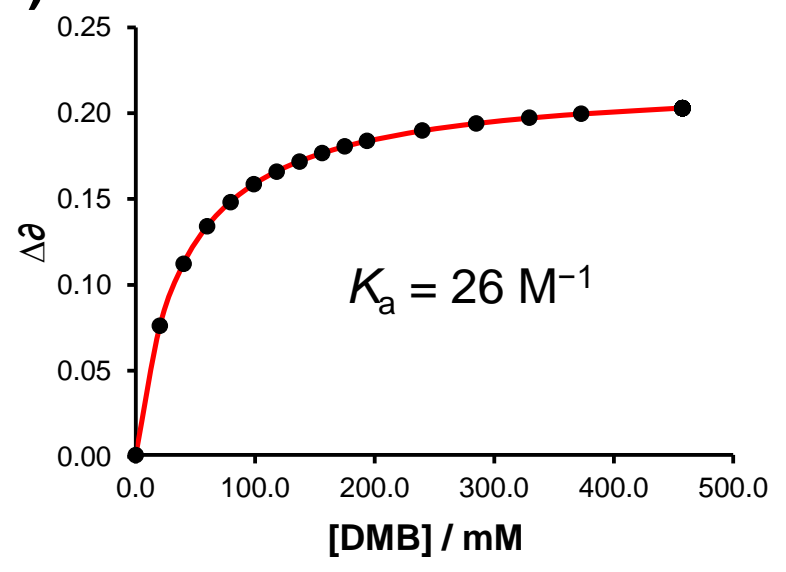

e)

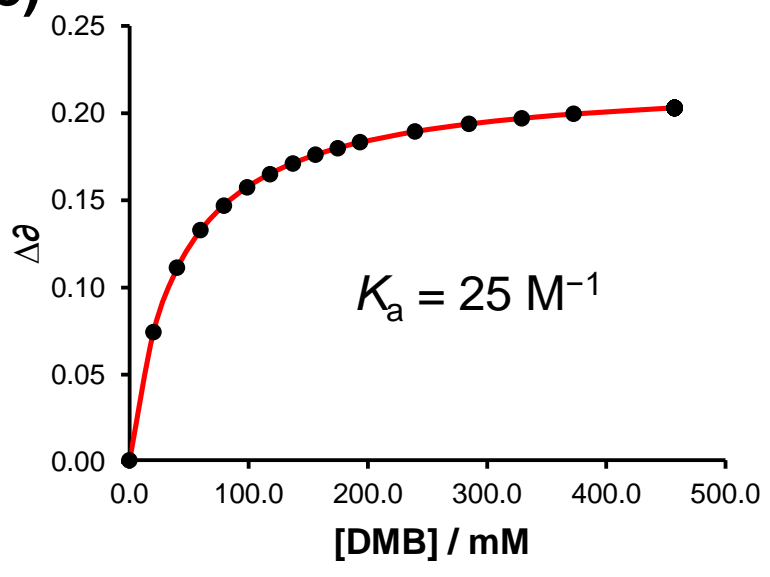

Figure S14. ${ }^{1} \mathrm{H}$ NMR titration of $1.4 \mathrm{PF}_{6}$ with $\mathrm{DMB}$ in $\mathrm{CD}_{3} \mathrm{CN}$ at room temperature. a) Downfield portion of the ${ }^{1} \mathrm{H}$ NMR spectra showing the shift of protons of the bipyridinium units and the resonances for the aromatic protons of the DMP units upon addition of DMB. b) Upfield portion of the ${ }^{1} \mathrm{H}$ NMR spectra showing the shift of the resonances for the methoxy protons upon addition of DMB. c) Central portion of the ${ }^{1} \mathrm{H}$ NMR spectra depicting the separation of the broad peak for the methylene protons into two broad peaks. In d) and e) binding curves from repeated titration experiments are shown displaying the change of the chemical shift for the proton at $\delta=7.15 \mathrm{ppm}$ when $[G]=0$ ) against the guest concentration based on a 1:1 binding isotherm. 
Isothermal titration was performed by TA Nano Isothermal Titration Calorimeter at $25{ }^{\circ} \mathrm{C}$. A hastelloy cell was used with an active cell volume $190 \mu \mathrm{L}$. The stirring speed was set at $75 \mathrm{rpm}$. Receptor and substrate solutions were prepared in anhydrous $\mathrm{MeCN}$ and allowed to equilibrate overnight. In each titration experiment, a solution of receptor $(1 \mathrm{mM})$ was placed in the titration cell while its substrates were loaded into the titration syringe. Generally, 20-25 injections were performed with gradually decreased titration peaks. The heat of dilution was measured separately by titrating the substrate into a blank solution. After subtracting the heat of dilution, the resulting data were analyzed with NanoAnalyze software using a 1:1 binding model and plotted by Origin Lab 8.6 software. All of the titrations were independently duplicated - shown below is one set of titration isotherms - and all isotherm fittings were used to calculate the average $K_{\mathrm{a}}$ and $\Delta H$ with relevant standard errors.
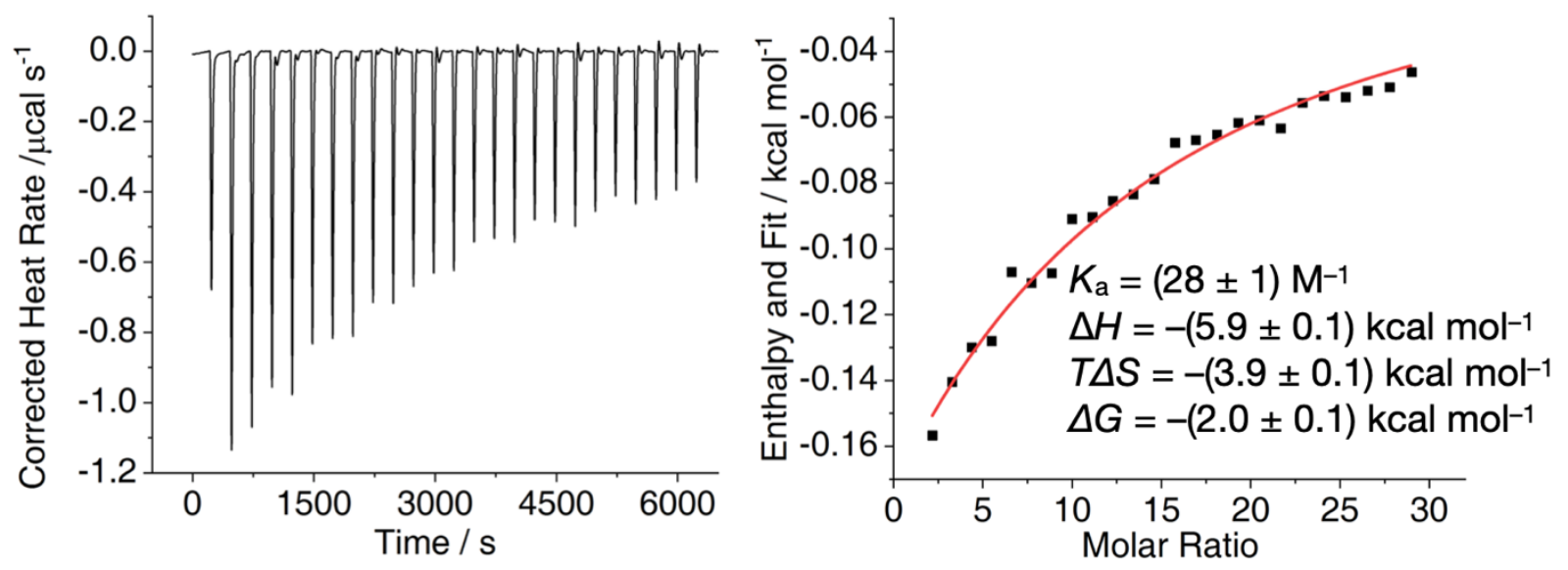

Figure S15. ITC Profile between 1.4PF 6 ( $1 \mathrm{mM}$, in cell) and DMB (200 mM, in syringe) at $25^{\circ} \mathrm{C}$ in $\mathrm{MeCN}$ (left) and nonlinear fitting of enthalpy (right).

\section{Binding studies between $1 \cdot 2 \mathrm{PF}_{6}$ and $\mathrm{MV} \cdot \mathrm{PF}_{6}$}

Prior to titrations, $\mathrm{MeCN}$ was degassed using the freeze-pump-thaw method and subsequently transferred to a flask containing activated molecular sieves ( $3 \AA$ ) which had been previously activated by heating at $120^{\circ}$ under vacuum overnight. Titrations were performed inside a glovebox by adding a $24 \mu \mathrm{M}$ or $32 \mu \mathrm{M}$ solution of $1 \cdot 2 \mathrm{PF}_{6}$ and $4.8 \mathrm{mM}$ or $6.4 \mathrm{mM} \mathrm{MV} \cdot \mathrm{PF}_{6}$ in $\mathrm{MeCN}$ to a $24 \mu \mathrm{M}$ or $32 \mu \mathrm{M}$ solution of $\mathbf{1} \cdot 2 \mathrm{PF}_{6}$ in $\mathrm{MeCN}$, respectively. After each addition a UV-Vis-NIR spectra was recorded outside the glovebox with the aid of a cap sealed UV Quartz cuvette. The spectra were stacked using OriginPro $8.5 S R I$ and absorption changes upon addition of substrate 
were fitted to a 1:1 binding isotherm using an Excel spreadsheet, 14allMaster.xls, developed by Professor Christopher A Hunter (University of Cambridge).

a)

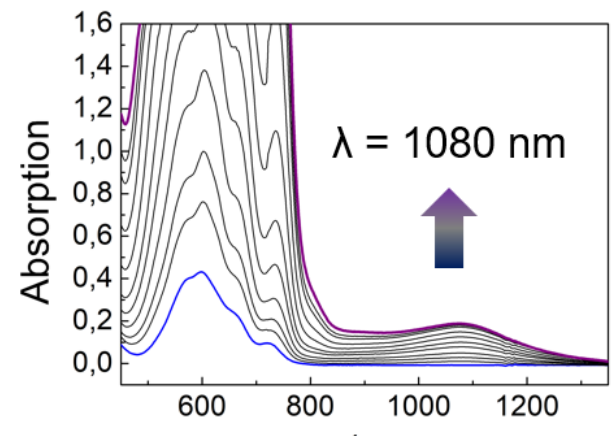

C)

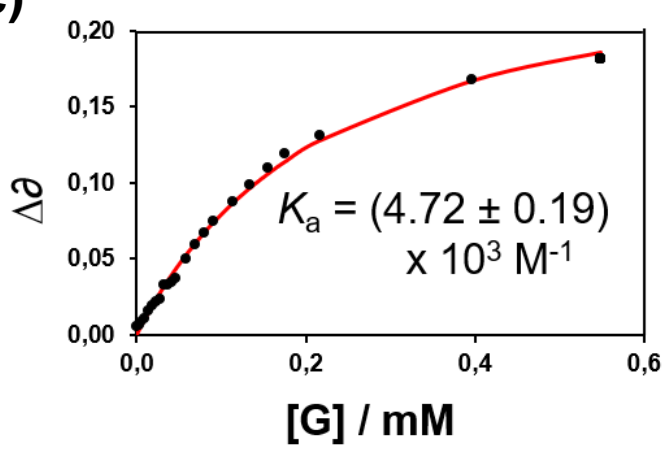

b)

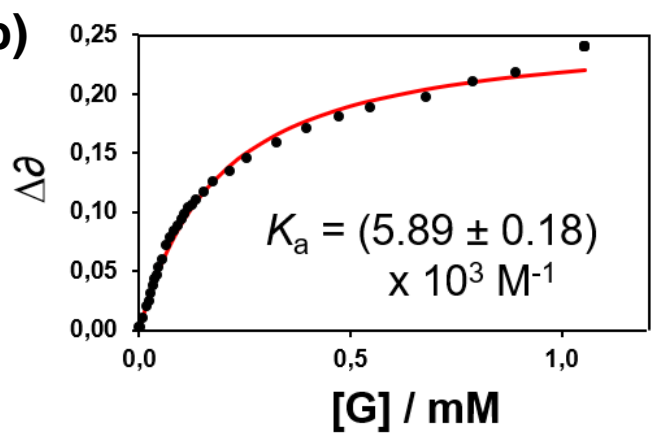

d)

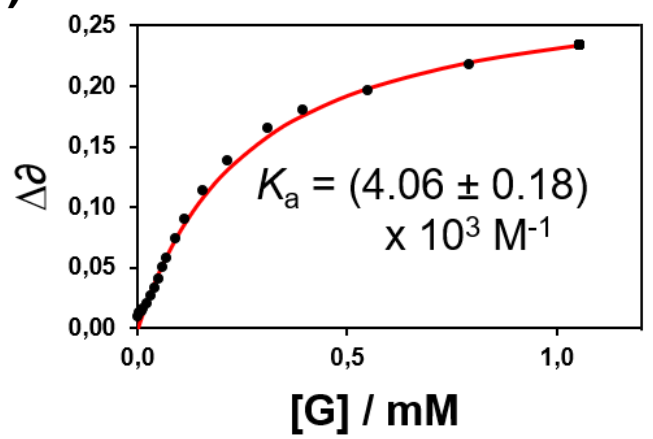

Figure S16. UV-Vis-NIR titration of $1 \cdot 2 \mathrm{PF}_{6}$ with $\mathrm{MV} \cdot \mathrm{PF}_{6}$ in $\mathrm{MeCN}$ at room temperature. a) UV-Vis-NIR spectra depicting the increase in the absorption band at $\lambda=1080 \mathrm{~nm}$, indicating the trisradical tricationic inclusion complexation upon incremental addition of $\mathbf{M V} \cdot \mathrm{PF}_{6}$ to $1 \cdot 2 \mathrm{PF} 6$. b) Binding curve obtained when a host concentration of $24 \mu \mathrm{M}$ was used. In c) and d), binding curves are presented based on a host concentration of $32 \mu \mathrm{M}$.

\section{Density Functional Theory Calculations}

The Cartesian coordinates were taken from the X-ray single crystal data. The binding energies,

frontier molecular orbitals (FMOs), and spin density difference calculations were performed with

density functional theory (DFT) in the Orca program ${ }^{8}$ (version 4.1.2). Two levels of theory were

used, a lower level and a higher level. The former consists of a generalized gradient approximation 
(GGA) with 'built in' Grimme's second generation dispersion, B97D, and a Pople type double zeta basis set, diffusion and two polarization functions, $6-31+\mathrm{G}(\mathrm{d}, \mathrm{p}) .{ }^{9}$ The latter DFT level is the range-separated Becke three parameter Lee Yang Parr (CAM-B3LYP) hybrid functional, with an Ahlrich's triple zeta basis set with one polarization function (two was found to be too computationally costly) Def2-TZVP, and Grimme's third generation dispersion with Becke Johnson damping (D3BJ). To speed up the DFT optimizations, the resolution of the identity (RI) for the B97D functional and the Coulomb integral and numerical chain-of-sphere integration for the HF exchange ${ }^{12,13}$ (RIJCOSX) for the CAM-B3LYP functional, was applied with the Def2/J auxiliary basis ${ }^{14}$ (AuxJ). The orbitals and densities were visualized with the ChemCraft program (version 574b).

1

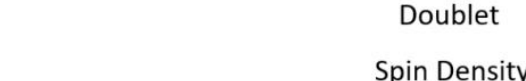

Spin Density

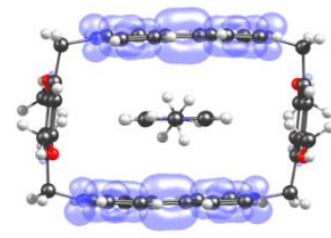

CAM-B3LYP/Def2TZVP/D3BJ

B97-D/6-31+G(d,p)

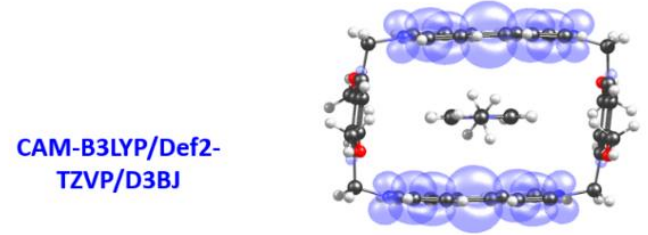

Quartet

Spin Density
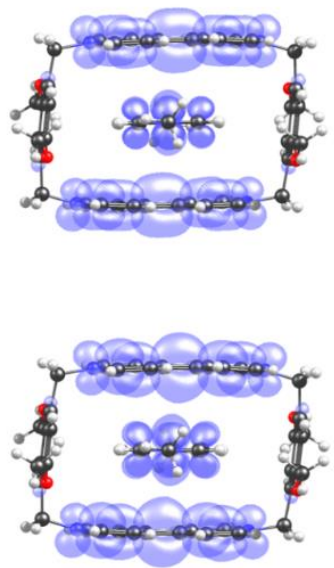

Figure S17. The spin density difference for $1 \supset \mathbf{M V}^{\left(3^{\bullet+}\right)}$ in the doublet and quartet states 


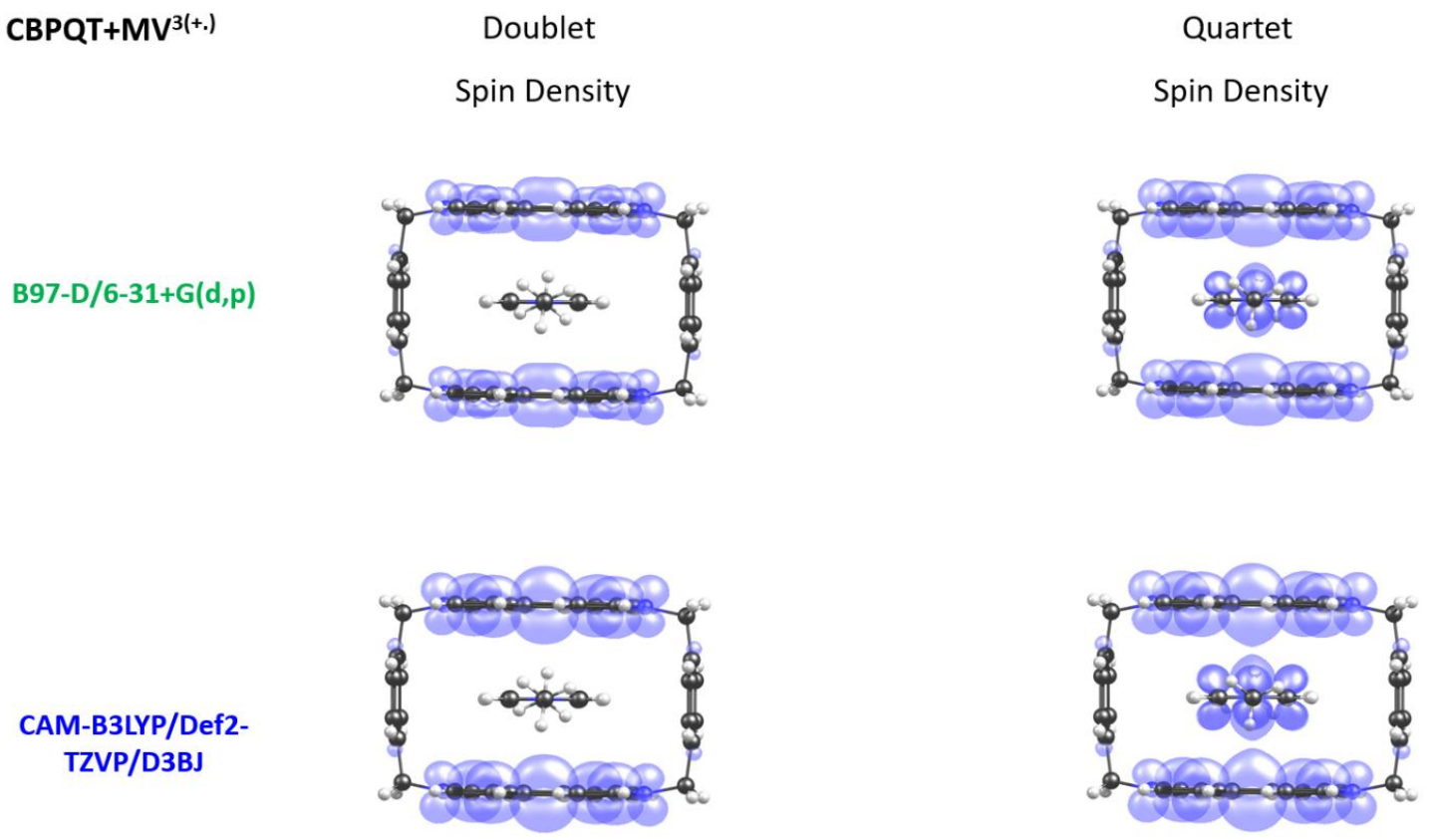

Figure S18. The spin density difference for CBPQTدMV $\mathbf{M}^{\left(3^{\circ+}\right)}$ in the doublet and quartet states

\begin{tabular}{|c|c|c|c|c|c|}
\hline & & \multicolumn{4}{|c|}{ Quartet FMO energy levels (eV) } \\
\hline & & 1 & $1.3 \mathrm{PF}_{6}^{-}$ & CBPQT+MV ${ }^{3(+.)}$ & 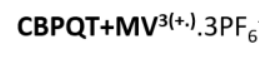 \\
\hline$\Psi_{\mathrm{L}}$ & $\underline{-}$ & $-9.21-7.77$ & $-3.18-1.70$ & $-9.48-8.08$ & $-4.24-3.09$ \\
\hline$\Psi_{\mathrm{H}}$ & 1 & $-10.31-12.06$ & $-4.29-6.07$ & $-10.59-12.30$ & $-4.70-6.49$ \\
\hline$\Psi_{\mathrm{H}-1}$ & 1 & $-10.61-12.48$ & $-4.74-6.60$ & $-11.00-12.85$ & $-5.57-7.58$ \\
\hline$\Psi_{\mathrm{H}-2}$ & 1 & $-11.18-13.15$ & $-5.09-7.07$ & $-11.51-13.48$ & $-5.84-8.43$ \\
\hline$\Psi_{\mathrm{H}-3}$ & $1 !$ & $-11.78-14.13$ & $-5.81-8.48$ & $-13.31-15.59$ & $-5.84-8.98$ \\
\hline
\end{tabular}

B97-D/6-31+G(d,p)

CAM-B3LYP/Def2-TZVP/D3BJ

Figure S19. The quartet FMO energy levels $(\mathrm{eV})$ for $[1 \mathrm{DMV}]^{(3 \cdot+)}, 1 \cdot 3 \mathrm{PF}_{6}^{-},[\mathrm{CBPQT} \mathrm{MMV}]^{(3 \cdot+)}$, and [CBPQTدMV]•3PF 6 
a)

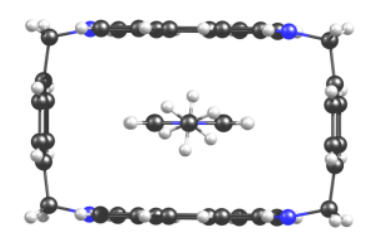

Binding Energy / $\mathrm{kcal} \mathrm{mol}^{-1}$

\begin{tabular}{ccc} 
Complex & $\begin{array}{c}\mathrm{B} 97-\mathrm{D} / \\
6-31+\mathrm{G}(\mathrm{d}, \mathrm{p})\end{array}$ & $\begin{array}{c}\text { CAM-B3LYP/ } \\
\text { Def2-TZVP/D3BJ }\end{array}$ \\
\hline [CBPQTدMV] $^{3(+)}$ Doublet & +53.66 & +66.97 \\
[CBPQTدMV] $^{3(+\cdot)}$ Quartet & +68.68 & +75.28 \\
[CBPQTدMV] $^{3(+\cdot)}$ Double - quartet & -15.02 & -8.31
\end{tabular}

b)

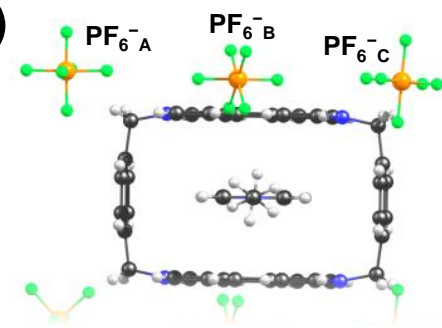

\begin{tabular}{|c|c|c|}
\hline \multirow[b]{2}{*}{$\begin{array}{l}\text { Interaction with } \\
\text { counterion }\left(\mathrm{PF}_{6}^{-}\right)\end{array}$} & \multicolumn{2}{|c|}{ Interaction Energy / kcal mol-1 } \\
\hline & $\begin{array}{c}\mathrm{B} 97-\mathrm{D} / \\
6-31+\mathrm{G}(\mathrm{d}, \mathrm{p})\end{array}$ & $\begin{array}{c}\text { CAM-B3LYP/ } \\
\text { Def2-TZVP/D3BJ }\end{array}$ \\
\hline [CBPQTدMV] $^{3(+\cdot) \ldots P_{6}{ }^{-} \mathrm{A}}$ & -128.07 & -124.94 \\
\hline$[C B P Q T د M V]^{3(+\cdot)} \ldots P^{-} F^{-}$ & -144.88 & -143.00 \\
\hline$[C B P Q T د M V]^{3(+\cdot) \ldots F_{6}{ }^{-} \mathrm{C}}$ & -132.10 & -130.31 \\
\hline 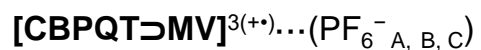 & -286.04 & -282.65 \\
\hline
\end{tabular}

c)
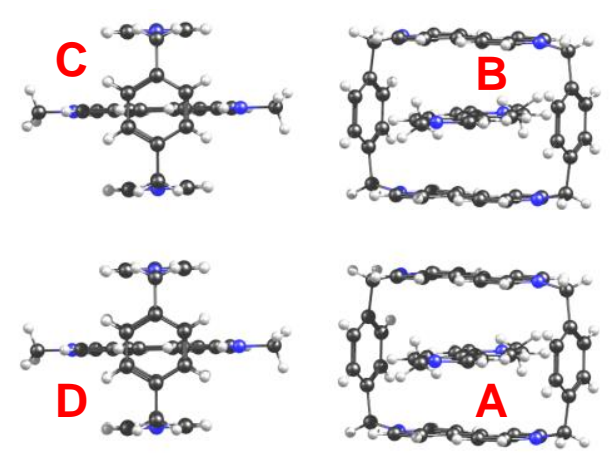

\begin{tabular}{ccc}
$\begin{array}{c}\text { Interactions } \\
\text { between } \\
\text { cyclophanes }\end{array}$ & $\begin{array}{c}\mathrm{B} 97-\mathrm{D} / \\
6-31+\mathrm{G}(\mathrm{d}, \mathrm{p})\end{array}$ & $\begin{array}{c}\text { CAM-B3LYP/ } \\
\text { Def2-TZVP/D3BJ }\end{array}$ \\
\hline $\mathrm{A} \cdots \mathrm{B}_{\text {(doublet-doublet) }}$ & +247.47 & +256.55 \\
$\mathrm{~A} \cdots \mathrm{C}_{\text {(doublet-doublet) }}$ & +218.62 & +220.00 \\
$\mathrm{~A} \cdots \mathrm{D}_{\text {(doublet-doublet) }}$ & +177.59 & +194.87 \\
$\mathrm{~A} \cdots \mathrm{B}_{\text {(quartet-quartet) }}$ & $*$ & +259.35 \\
$\mathrm{~A} \cdots \mathrm{C}_{\text {(quartet-quartet) }}$ & +218.89 & +219.99 \\
$\mathrm{~A} \cdots \mathrm{D}_{\text {(quartet-quartet) }}$ & +178.17 & +178.25
\end{tabular}

Figure S20. Calculated binding energy interactions in the solid state for both the doublet and quartet states at two levels of DFT as color-coded: green (B97D/6-31+G(d,p)) and blue (CAM-B3LYP/Def2-TZVP/D3BJ).

a) The structure and bindings of [CBPQTدMV] ${ }^{3(+)}$; b) the structure and bindings of [CBPQTدMV]•3PF

c) the solid state superstructure interactions between [CBPQTدMV] $]^{3(+)}$ units; *unable to converge. 
a)

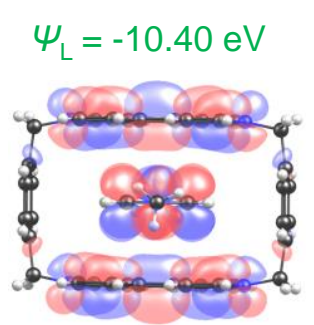

$\Delta E_{\mathrm{H}-\mathrm{L}}=0.55 \mathrm{eV}$

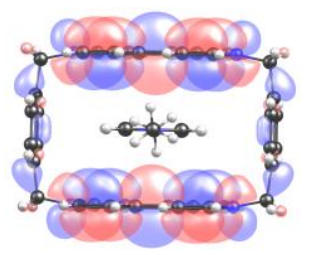

$$
\psi_{\mathrm{H}}=-10.95 \mathrm{eV}
$$

B97-D/ $6-31+G(d, p)$
Doublet State

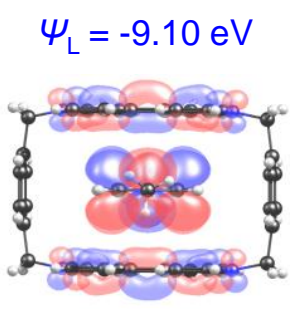

$$
\Delta E_{\mathrm{H}-\mathrm{L}}=3.62 \mathrm{eV}
$$

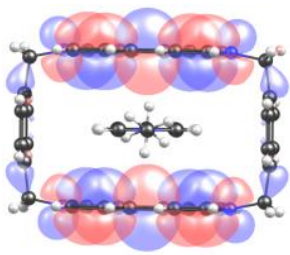

$\Psi_{H}=-12.72 \mathrm{eV}$

CAM-B3LYP/

Def2-TZVP/D3BJ b)

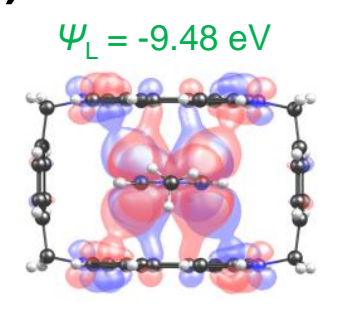

$\Delta E_{\mathrm{H}-\mathrm{L}}=1.11 \mathrm{eV}$

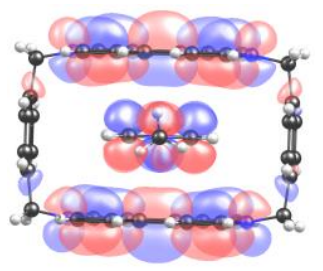

$$
\psi_{\mathrm{H}}=-10.59 \mathrm{eV}
$$

B97-D/ $6-31+G(d, p)$
Quartet State

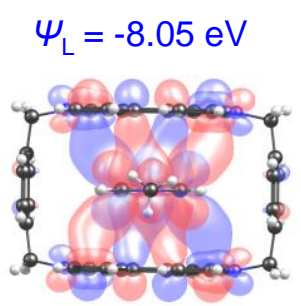

$$
\Delta E_{\mathrm{H}-\mathrm{L}}=4.25 \mathrm{eV}
$$

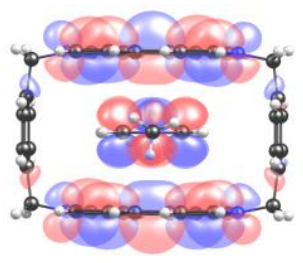

$\Psi_{\mathrm{H}}=-12.30 \mathrm{eV}$

CAM-B3LYP/

Def2-TZVP/D3BJ

Figure S21. The highest occupied molecular orbitals (HOMOs) and lowest unoccupied molecular orbitals (LUMOs) of CBPQTدMV ${ }^{(3+)}$ in both the doublet (a) and quartet (b) states, using both B-97D/6-31+G(d,p) (green) and CAM-B3LYP/Def2-TZVP/D3BJ (blue) levels of theory.

\section{Electron Paramagnetic Resonance Spectroscopy}

Continuous-wave EPR measurements were made at X-band $(\sim 9.6 \mathrm{GHz})$ using a Bruker Elexsys E580-X EPR spectrometer outfitted with a Bruker super high Q resonator (ER4122-SHQE). Experiments were performed using non-saturating microwave power, and $0.05 \mathrm{mT}$ modulation amplitude at $100 \mathrm{kHz}$.

Pulsed EPR measurements were performed on a Bruker Elexsys E-680-X/W EPR spectrometer equipped with a split ring resonator (ER4118X-MS5). A $1 \mathrm{~kW}$ TWT amplifier (Applied Systems Engineering 117X) was employed to generate high-power microwave pulses. The resonator was 
partially overcoupled to maximize echo intensity and minimize ringing following microwave pulses. The nutation spectra were collected using a three pulse sequency, Pnut-T- $\pi / 2-\tau-\pi$, where the nutation pulse, Pnut was varied in length effecting a nutation of the magnetization about an axis perpendicular to the magnetic field in the laboratory.

\section{SQUID Measurements}

Dc magnetic studies on $[\mathbf{1} \mathbf{M V}] \cdot 3 \mathrm{PF}_{6}$ were measured on a Quantum Design SQUID magnetometer. Data for $[\mathbf{1} \mathbf{D M V}] \cdot 3 \mathrm{PF}_{6}(11 \mathrm{mg})$ were measured from 1.80 to $300 \mathrm{~K}$ with the sample sealed in a gelatin capsule with an applied field of 10000 Oe. Although data collection was obtained multiple times, in the temperature range, $150-250 \mathrm{~K}$, the signal-to-noise ratio is critical. For that reason, only data obtained at temperatures up to $180 \mathrm{~K}$ are interpreted.

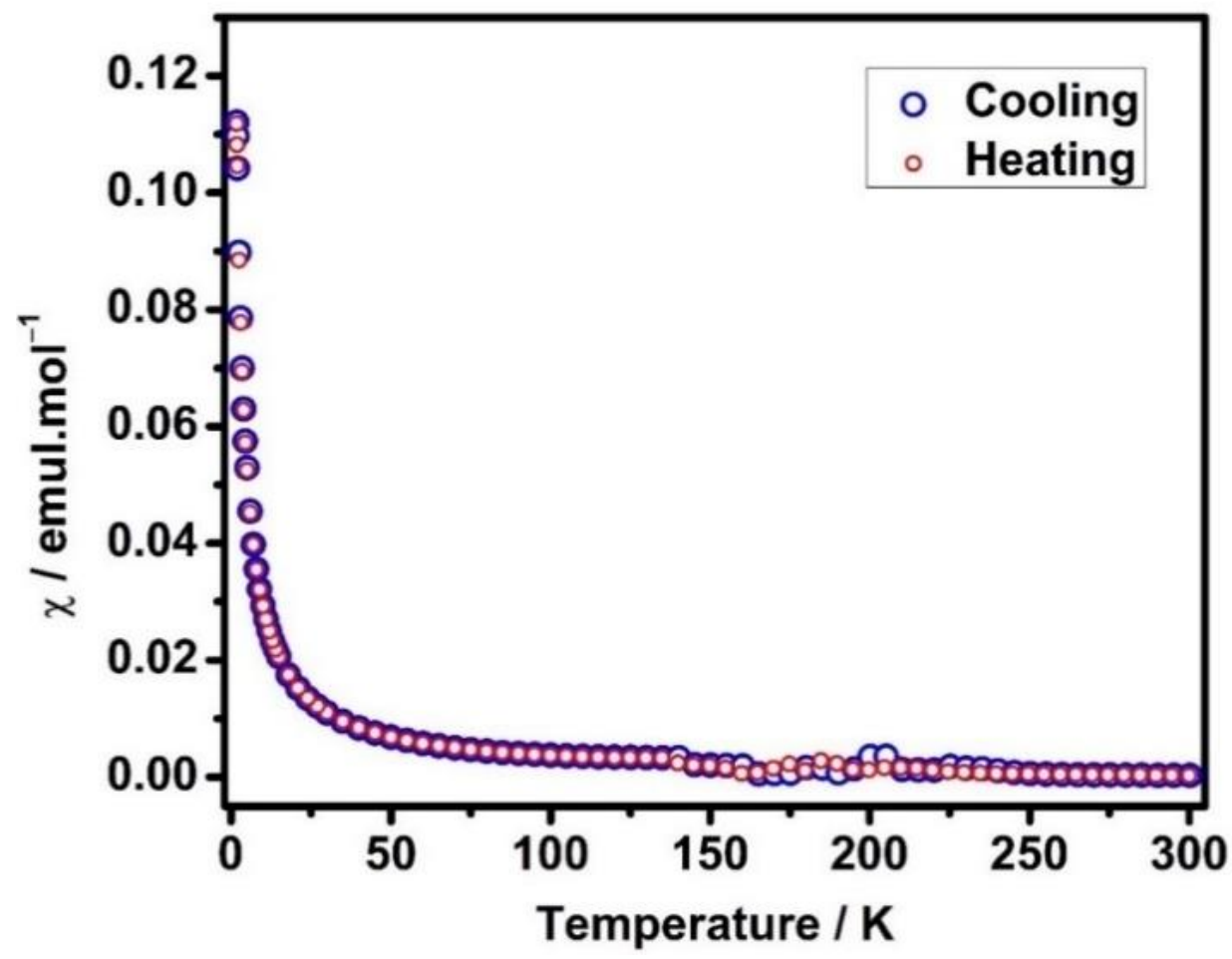

Figure S22. Temperature dependence of the magnetic susceptibility of [1دMV]•3PF 6 in heating and cooling at a temperature range of $1.80-300 \mathrm{~K}$. 


\section{References}

(1) Roviello, A.; Borbone, F.; Carella, A.; Diana, R.; Roviello, G.; Panunzi, B.; Ambrosio, A.; Maddalena, P. High quantum yield photoluminescence of new polyamides containing oligo-PPV amino derivatives and related oligomers. J. Polym. Sci. A. Polym. Chem. 2009, 47, 2677-2689.

(2) Dolomanov, O. V.; Bourhis, L. J.; Gildea, R. J.; Howard, J. A. K.; Puschmann, H. OLEX2: a complete structure solution, refinement and analysis program. J. Appl. Crystallogr. 2009, 42, 339341.

(3) Sheldrick, G. A. SHELXT - Integrated space-group and crystal-structure determination. Acta. Crystallogr. Sect. A 2015, 71, 3-8.

(4) Sheldrick, G. A. A short history of SHELX. Acta. Crystallogr. Sect. A 2008, 64, 112-122.

(5) Devonport, W.; Blower, M. A.; Bryce, M. R.; Goldenberg, L. M. A redox-active tetrathiafulvalene [2]pseudorotaxane: Spectroelectrochemical and cyclic voltammetric studies of the highly-reversible complexation/decomplexation process. J. Org. Chem. 1997, 62, 885-887.

(6) Benniston, A. C.; Harriman, A.; Philp, D.; Stoddart, J. F. Charge recombination in cyclophanederived, intimate radical ion pairs. J. Am. Chem. Soc. 1993, 115, 5298-5299.

(7) Thordarson, P. Determining association constants from titration experiments in supramolecular chemistry. Chem. Soc. Rev. 2011, 40, 1305-1323.

(8) Neese, F. The ORCA program system. 2012, Wiley Interdiscip. Rev.: Comput. Mol. Sci. 2, 73-78.

(9) Geraskina, M. R.; Dutton, A. S.; Juetten, M. J.; Wood, S. A.; Winter, A. H. The viologen cation radical pimer: A case of dispersion-driven bonding Angew. Chem., Int. Ed. 2017, 56, 9435-9439.

(10) Becke, A. D. Density functional thermochemistry. III. The role of exact exchange. J. Chem. Phys. 1993, 98, 5648-5652.

(11) Weigend, F.; Ahlrichs, R. Balanced basis sets of split valence, triple zeta valence and quadruple zeta valence quality for $\mathrm{H}$ to Rn: Design and assessment of accuracy. Phys. Chem. Chem. Phys. 2005, 7, 3297-3305.

(12) Neese, F. An Improvement of the resolution of the identity approximation for the calculation of the Coulomb matrix, J. Comp. Chem. 2003, 24, 1740-1747.

(13) Izsák, R.; Neese, F. An overlap fitted chain of spheres exchange method, J. Chem. Phys. 2011, 135, 144105.

(14) (a) Weigend, F. Accurate Coulomb-fitting basis sets for H to Rn. Phys. Chem. Chem. Phys. 2006, 8, 1057-1065. (b) Stoychev, G. L.; Auer, A. A.; Neese, F. Automatic generation of auxiliary basis sets. J. Theo. Comp. Chem. 2017, 13, 554-562.

(15) Barone, V.; Cossi, M. Quantum calculation of molecular energies and energy gradients in solution by a conductor solvent model. J. Phys. Chem. A, 1998, 102, 1995-2001. 